\title{
Regulation of p73 by Hck through kinase-dependent and independent mechanisms
}

\author{
Preeti Paliwal, Vegesna Radha* and Ghanshyam Swarup*
}

Address: Centre for Cellular and Molecular Biology, Uppal Road, Hyderabad-500007, India

Email: Preeti Paliwal - preeti@ccmb.res.in; Vegesna Radha* - vradha@ccmb.res.in; Ghanshyam Swarup* - gshyam@ccmb.res.in

* Corresponding authors

Published: 30 May 2007

BMC Molecular Biology 2007, 8:45 doi:10.1 186/147I-2199-8-45

This article is available from: http://www.biomedcentral.com/I47|-2/99/8/45

(C) 2007 Paliwal et al; licensee BioMed Central Ltd.

This is an Open Access article distributed under the terms of the Creative Commons Attribution License (http://creativecommons.org/licenses/by/2.0), which permits unrestricted use, distribution, and reproduction in any medium, provided the original work is properly cited.
Received: 28 November 2006

Accepted: 30 May 2007

\begin{abstract}
Background: p73, a p53 family member is a transcription factor that plays a role in cell cycle, differentiation and apoptosis. 733 is regulated through post translational modifications and protein interactions. c-Abl is the only known tyrosine kinase that phosphorylates and activates p73. Here we have analyzed the role of Src family kinases, which are involved in diverse signaling pathways, in regulating $\mathrm{P} 73$.
\end{abstract}

Results: Exogenously expressed as well as cellular Hck and p73 interact in vivo. In vitro binding assays show that SH3 domain of Hck interacts with p73. Co-expression of p73 with Hck or c-Src in mammalian cells resulted in tyrosine phosphorylation of $\mathrm{p} 73$. Using site directed mutational analysis, we determined that Tyr-28 was the major site of phosphorylation by Hck and c-Src, unlike c-Abl which phosphorylates Tyr-99. In a kinase dependent manner, Hck co-expression resulted in stabilization of p73 protein in the cytoplasm. Activation of Hck in HL-60 cells resulted in tyrosine phosphorylation of endogenous p73. Both exogenous and endogenous Hck localize to the nuclear as well as cytoplasmic compartment, just as does p73. Ectopically expressed Hck repressed the transcriptional activity of p73 as determined by promoter assays and semi-quantitative RT-PCR analysis of the p73 target, Ipaf and MDM2. SH3 domain- dependent function of Hck was required for its effect on p73 activity, which was also reflected in its ability to inhibit p73-mediated apoptosis. We also show that Hck interacts with Yes associated protein (YAP), a transcriptional co-activator of $\mathrm{p} 73$, and shRNA mediated knockdown of YAP protein reduces p73 induced Ipaf promoter activation.

Conclusion: We have identified p73 as a novel substrate and interacting partner of Hck and show that it regulates p73 through mechanisms that are dependent on either catalytic activity or protein interaction domains. Hck-SH3 domain-mediated interactions play an important role in the inhibition of p73-dependent transcriptional activation of a target gene, Ipaf, as well as apoptosis.

\section{Background}

p73 is a transcription factor that shares significant homology with the tumor suppressor protein p53 and mediates cellular functions such as cell cycle arrest, differentiation, senescence and apoptosis [1,2]. Alternate promoter usage and splicing give rise to p73 variants differing at the $\mathrm{N}$ and C-terminus, p73 $\alpha$ and $\beta$ forms being the predominant transactivation competent forms $[3,4]$. p73 and p53 bind common response elements and transactivate an overlapping set of target genes, though with 
differing efficiencies [1,5-7]. p73 knockout mice exhibit severe neurological, inflammatory and pheromonal defects but lack spontaneous tumor formation [8]. Forced expression of p73 activates target genes like p21, Bax, IGF BP3, CyclinG, Mdm2, caspase-1, etc and promotes apoptosis in both p53 positive as well as negative cell lines $[1,5-7,9]$.

Cellular p73 protein is maintained at very low levels and activation is controlled at transcriptional as well as posttranslational levels. p73 is induced in response to a range of DNA damaging agents as well as during differentiation of many cell types [10]. Multiple mechanisms like posttranslational modifications, protein-protein interaction and sub-cellular compartmentalization regulate transactivation potential and apoptosis inducing property of $\mathrm{p} 73$ $[10,11]$. Several viral and cellular proteins interact with p73 and regulate its activity [3]. While some of the interacting proteins enhance transactivation potential of $\mathrm{p} 73$ by stabilizing it [12-14], others inhibit transactivation property of p73 [15-20]. p73 is also known to interact with and cooperate with other transcription factors to regulate gene expression $[9,21]$. Interaction with c-Abl through SH3 domain in response to DNA damage results in phosphorylation at Tyr99, stabilization and activation $[12,22,23]$. c-Abl can also activate p38 MAP kinase to phosphorylate p73 leading to its stabilization [24].

Src family kinases (SFKs) are non receptor tyrosine kinases involved in the regulation of diverse cellular functions like proliferation, differentiation, survival, adhesion, motility and angiogenesis [25]. Apart from a catalytic domain, they possess $\mathrm{SH} 2, \mathrm{SH} 3$ and $\mathrm{SH} 4$ domains required for sub-cellular targeting and protein interaction and therefore have cellular functions dependent on catalytic activity as well as protein interaction domains $[26,27]$. Hck is a SFK showing restricted expression in hematopoietic cells of myeloid and monocytic lineage and in embryonic stem cells [28-30]. It exists as two isoforms (p61 and p59 in humans), which arise due to alternate translational start sites [31]. Hck is activated in response to cytokines and is an important component of signaling pathways in activated macrophages [32-34]. Hck levels increase during differentiation of monocytes and it plays a role in phagocytosis, adhesion, respiratory burst, granule secretion and apoptosis [35-37]. Several proteins like Cbl, Stat-3, WASP, WIP, ELMO, ACK1 and C3G interact with Hck through its SH3 domain [36-40]

The mechanisms that regulate stability and pro-apoptotic activity of p73 are distinct from those used by p53 and regulation by tyrosine phosphorylation has been shown only for p73 [23]. Though initial studies described Tyr-99 as the major site of phosphorylation by cAbl, it has been shown that several other tyrosine residues are also tar- geted [41]. But thus far, no other tyrosine kinase has been described to phosphorylate or regulate p73 activity. Hck interacts with c-Abl and they modulate each other's activity [42]. Given the role of SFKs in mediating survival and apoptotic pathways in cells, we investigated the role of Hck in regulating p73 activity and function. Our results identify p73 as a novel interacting partner and substrate of Hck, and that Hck regulates p73 through kinase dependent as well as independent functions. We also provide evidence for functional interaction between p73 and Hck leading to regulation of p73 induced apoptosis.

\section{Results}

\section{Hck interacts with p73 $\alpha$}

We explored the possibility of p73 interacting with Hck in vivo in co-immunoprecipitation experiments. p73 was detected in Hck immunoprecipitates from cells expressing both Hck and p73, but not in cells expressing p73 alone suggesting their interaction in mammalian cells (Fig. 1A). p73 has polyproline sequences that could serve as interacting motifs for $\mathrm{SH} 3$ domain containing proteins. To determine whether Hck and p73 form a complex through SH3-polyproline mediated interaction, in vitro binding experiments were carried out using glutathione-S-transferase (GST) fusion proteins. Recombinant fusion protein of GST with SH3 domain of Hck (GST-SH3 Hck) bound to Glutathione Sepharose beads was incubated with lysates of Cos 1 cells transfected with p $73 \alpha$ and p $73 \delta$. p $73 \delta$ is the shortest isoform which lacks the entire C-terminus including the SAM domain[3]. p73 $\alpha$ and p73 $\delta$ bound to GST-SH3-Hck and not with GST alone (Fig. 1B). Further, recombinant fusion protein of $\mathrm{SH} 3$ domain mutant (W93A) disabled for interaction (GST-mSH3 Hck) and GST-SH3-Hck were incubated with lysates of Cos1 cells transfected with p73 $\alpha$. p73 $\alpha$ bound to GST-SH3-Hck and not to GST or GST-mSH3-Hck (whose levels were comparable) (Fig. 1C). It has been shown that upon dimethyl sulfoxide (DMSO) treatment of HL-60 cells, both mRNA and protein levels of p $73 \alpha$ increase in a time dependent manner [43]. Hck levels are also known to increase under these conditions [44]. To examine whether endogenous p73 interacts with Hck under these conditions, we subjected lysates of differentiated HL-60 cells to immunoprecipitation using Hck antibody. Western blotting with p73 antibody showed that p73 $\alpha$ was co-immunoprecipitated with Hck and not with control antibody (Fig. 1D). Our results suggest that endogenous Hck and p73 interact under physiological conditions.

\section{Hck co-expression results in phosphorylation of p73}

Since p73 interacted with Hck, the possibility of p73 being a substrate of Hck in vivo was explored. Cos 1 cells were transfected with HA-p73 $\alpha$ expression construct with and without Hck and whole cell lysates subjected to western blotting with anti-phosphotyrosine antibody. When 
A

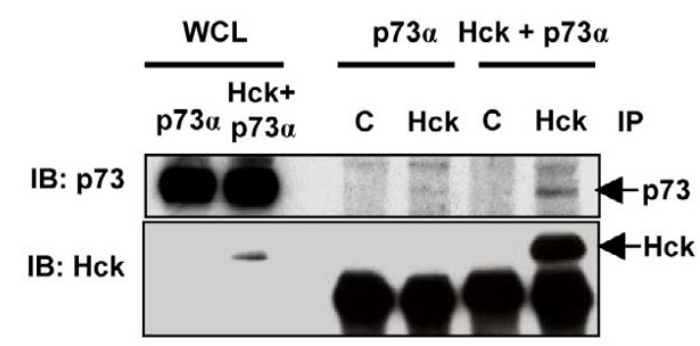

B

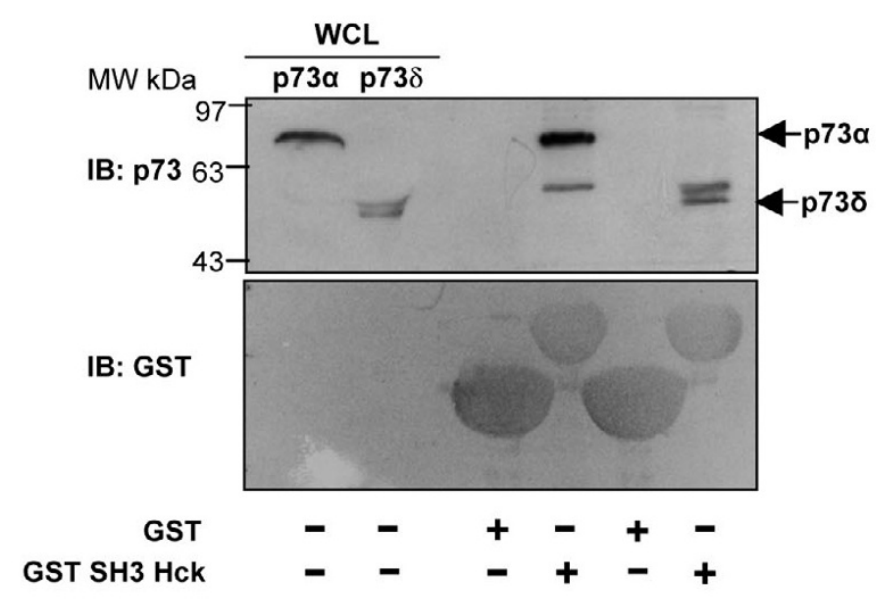

D

C
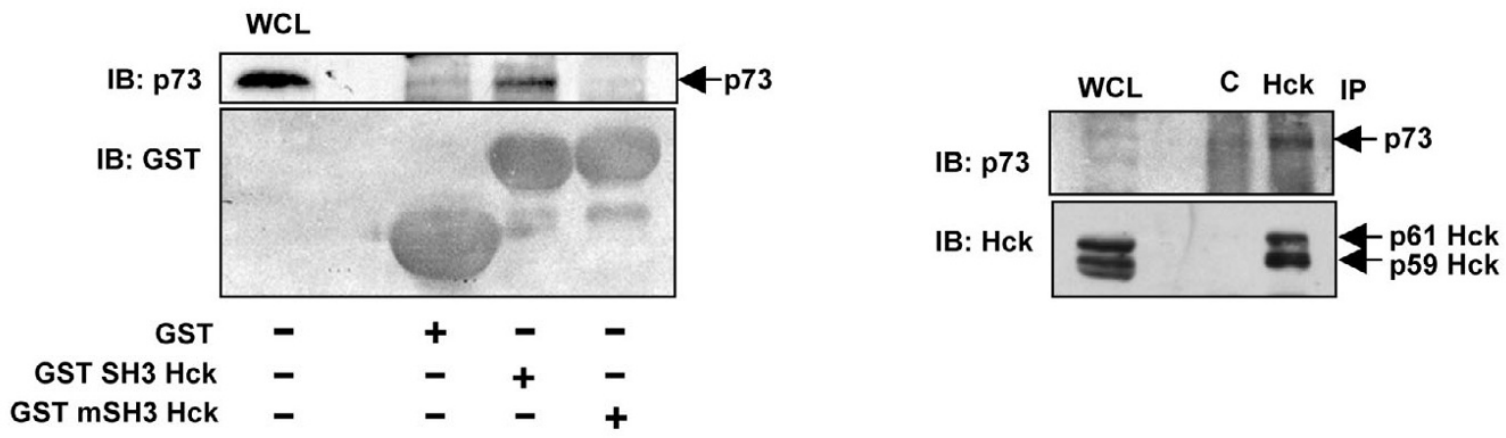

Figure I

Hck interacts with p73 $\alpha$ in vitro and in vivo. (A) Cos I cells transiently expressing HA-p 73 $\alpha$ alone or with Hck were immunoprecipitated with control rabbit lgG (C) or Hck polyclonal antibody. The immunoprecipitates were resolved by SDSPAGE and subjected to western blotting to detect p73 and Hck. (B) GST fusion proteins bound to Glutathione-Sepharose beads were incubated with lysates of CosI cells overexpressing $p 73 \alpha$ and p $73 \delta$. Bound proteins were subjected to western blotting to detect p73. (C) GST-SH3 Hck and GST-mSH3 Hck recombinant fusion proteins bound to Glutathione-Sepharose beads were incubated with lysates of CosI cells overexpressing $\mathrm{p} 73 \alpha$ and bound proteins were subjected to western blotting with p73 antibody. (D) Lysates of differentiated HL-60 cells (DMSO I.25\%) were immunoprecipitated with control rabbit IgG or Hck antibodies and subjected to western blotting for p73 and Hck. (WCL indicates whole cell lysate).

p73 was co-expressed with Hck, phosphotyrosine was seen on the polypeptide corresponding to p73 in mobility as detected by reprobing the blot using p73 antibody (Fig. 2A). Cells transfected with p73 or Hck alone did not show any corresponding phosphotyrosine containing peptides. Phosphorylation of p73 was dependent on kinase activity of Hck since co-expression of a catalytically inactive mutant KD-Hck (K269E) did not show tyrosine-phosphorylated polypeptide at the corresponding position (Fig. 2A). To confirm phosphorylation of p73 more directly, p73 was immunoprecipitated from cells expressing p73 $\alpha$ and Hck. Phosphorylated p73 could be detected in immunoprecipitates of p73 $\alpha$ with Hck over-expression whereas it was not observed with over-expressed KD-Hck (Fig. 2B, upper panel). Hck also phosphorylated p $73 \beta$, dependent on its kinase activity (data not shown). These results suggested that Hck expression could induce tyrosine phosphorylation of $\mathrm{p} 73 \alpha$ and $\beta$ in vivo. To check whether Hck phosphorylation on p73 is a direct event, in vitro phosphorylation assay was carried out. Recombinant GST and GST-p73 $\alpha$ bound to glutathione-Sepharose beads were incubated with purified Hck enzyme and $\gamma^{32} \mathrm{P}$ ATP. Proteins were analyzed by SDS-PAGE, stained and the gel dried for phosphor imaging. Hck phosphorylated GSTp73 $\alpha$ and not GST alone (Fig. 2C, right panel). Protein expression was visualized by commassie staining of the 
A

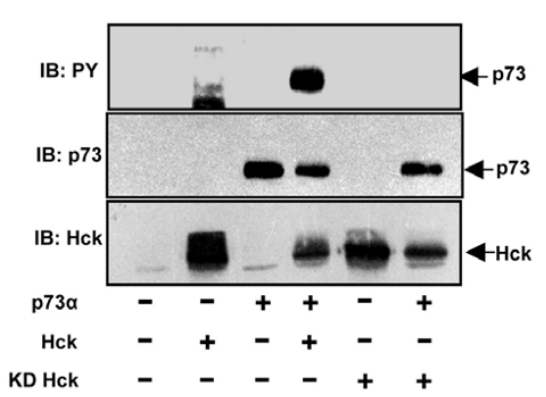

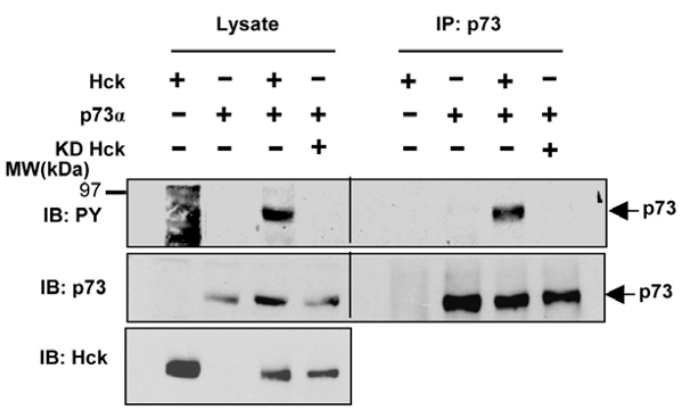

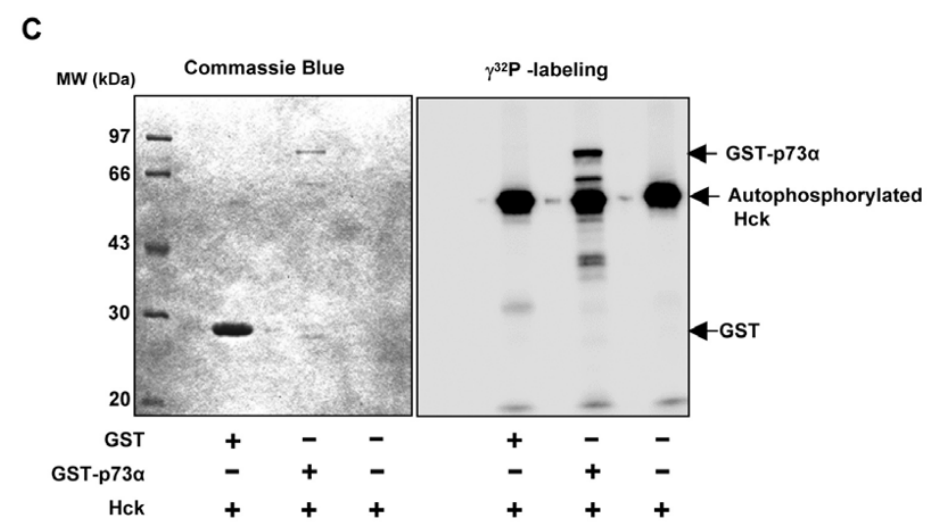

D

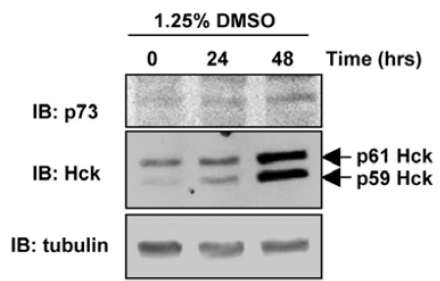

E

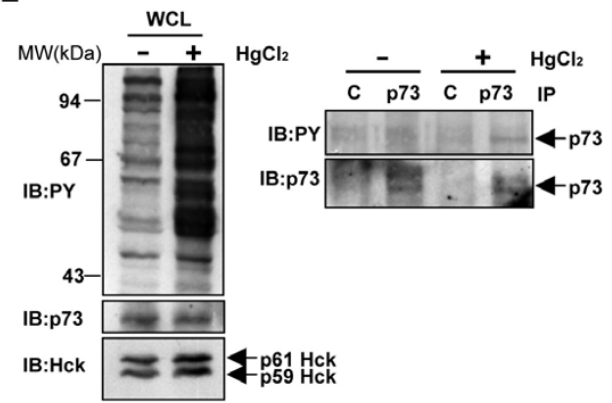

Figure 2

Hck phosphorylates p73 $\alpha$ in vivo and in vitro. (A) Whole cell lysates prepared from Cos I cells transfected with $\mathrm{HA}$-p73 $\alpha$ $(\mathrm{I} .6 \mu \mathrm{g})$ with and without Hck $(0.4 \mu \mathrm{g})$ expression constructs in the ratio of $4:$ I were subjected to immunoblotting with pTyr, p73 and Hck antibodies. (B) Cos I cells transfected with indicated expression constructs were subjected to immunoprecipitation with p73 antibody and immunoprecipitates analyzed for pTyr, p73 and Hck by western blotting. The amount of DNA was kept constant by addition of control vector pcDNA3. (C) Purified Hck protein ( $80 \mathrm{nM})$ was incubated with GST, GST-p73 $\alpha$ and alone with $\gamma^{32} \mathrm{P}-\mathrm{ATP}$ for 30 minutes at $37^{\circ} \mathrm{C}$ in an in vitro kinase assay. The proteins were analyzed by SDS-PAGE and stained with commassie blue (left panel). The gel was then dried and phosphorylated proteins visualized by phosphor imaging (right panel). (D) Western blot showing the endogenous protein levels of p73 and Hck upon differentiation with DMSO in HL60 cells. Tubulin expression was determined as a loading control. (E) Endogenous p73 gets phosphorylated on tyrosine upon activation of Hck. Western blot showing the phosphotyrosine content of cellular proteins and levels of endogenous $\mathrm{p73}$ and $\mathrm{Hck}$ upon $\mathrm{HgCl}_{2}$ treatment in differentiated $\mathrm{HL}-60$ cells (left panel). Lysates of diferentiated HL-60 cells treated with or without $\mathrm{HgCl}_{2}$ were subjected to immunoprecipitation with control (rabbit lgG) or p73 (rabbit polyclonal) antibody and western blotting performed with anti-phosphotyrosine antibody (right panel, upper portion) Immunoprecipitated p73 is shown in right panel, lower portion. 
gel prior to exposure (Fig. 2C, left panel). This result showed that Hck could directly phosphorylate $\mathrm{p} 73 \alpha$.

\section{Endogenous p73 gets tyrosine phosphorylated upon activation of Hck}

Treatment of myelomonocytic cell lines with mercuric chloride $\left(\mathrm{HgCl}_{2}\right)$ has been shown to specifically activate Hck, and has been used to identify substrates of Hck $[36,45,46]$. Treatment of HL-60 cells with DMSO showed an increase in protein levels of both p73 $\alpha$ and Hck (Fig. 2D). To find out whether endogenous p73 gets tyrosine phosphorylated upon activation of Hck, HL-60 cells were differentiated for 48 hours with DMSO and then subjected to $\mathrm{HgCl}_{2}$ treatment. The lysates were immunoprecipitated with p73 and control antibody. It was observed that endogenous p73 gets tyrosine phosphorylated upon activation of Hck as determined by western blotting with phosphotyrosine antibody (Fig. 2E, right panel). The left panel of Fig. 2E shows the western blots of whole cell lysate (WCL) with phosphotyrosine, p73 and Hck antibodies.

\section{Hck phosphorylates p73 $\alpha$ predominantly on Tyr28}

To identify the site of phosphorylation on $\mathrm{p} 73 \alpha$ by Hck, different tyrosine mutants were constructed by PCR based site directed mutagenesis in which tyrosine residues that are predicted targets for Src family tyrosine kinases (SFKs) were mutated to phenylalanine. Cos1 cells were transfected with $\mathrm{p} 73 \alpha$ or Y28F-p73 $\alpha$, Y121F-p73 $\alpha$, Y309Fp73 $\alpha, Y 355-356 F-p 73 \alpha$ in the presence of Hck and whole cell lysates subjected to western blotting with pTyr, p73 and Hck antibodies. All the mutants except Y28F-p73 $\alpha$ showed phosphorylation comparable to that seen on WTp73 $\alpha$ (Fig. 3A). Y28F-p73 $\alpha$ was compromised considerably in phosphorylation by Hck (Fig. 3A). This was not due to lower level of expression because p73 and Hck were comparable as determined by reprobing the blot with anti-p73 and anti-Hck antibody (Fig. 3A). c-Abl is a nonreceptor tyrosine kinase which phosphorylates $\mathrm{p} 73 \alpha$ on Y99 residue and activates it [23]. Hck induced phosphorylation of Y99F-p73 $\alpha$ as well as WT-p73 $\alpha$ while Y28Fp73 $\alpha$ was particularly compromised in phosphorylation (Fig. 3B). c-Src co-expression also resulted in p73 $\alpha$ phosphorylation predominantly on Y28 residue whereas expression of KD Src did not result in p73 phosphorylation (Fig. 3C). Taken together, our results suggest a novel site (Y28) of phosphorylation on $\mathrm{p} 73 \alpha$ by Src family kinases, which is different from c-Abl mediated phosphorylation of $\mathrm{p} 73$ on Y99 residue.

\section{Hck co-expression stabilizes p73}

To determine whether Hck affects p73 protein levels, Hela cells were transfected with p73 $\alpha$ alone or with Hck and whole cell lysates subjected to immunoblotting with anti p73 antibody. Co-expression of Hck but not KD-Hck showed higher $\mathrm{p} 73 \alpha$ protein levels (Fig. 4A). Hck also increased the protein levels of Y28F-p73 $\alpha$, which suggested that increase in $\mathrm{p} 73 \alpha$ protein level is not dependent on Y28 phosphorylation. The same blot was probed for Hck and GFP that was used as transfection efficiency control (Fig. 4A). These results suggest that Hck could increase the p73 protein levels in a kinase dependent manner. To examine whether p73 increase seen upon coexpression with Hck is due to effect on its stability, levels of p73 protein were determined in the presence of cycloheximide. p73 levels dropped significantly by 9 hours of cycloheximide treatment but did not change significantly when co-expressed with Hck (Fig. 4B) suggesting that Hck increases p73 protein stability.

\section{Sub-cellular localization of Hck and p73}

Since Hck is a non-receptor tyrosine kinase known to localize to plasma membranes, Golgi and in the cytoplasm [47-50] and p73 shows nucleo-cytoplasmic exchange, we investigated sub-cellular distribution of p73 $\alpha$ upon co-expression with Hck by biochemical fractionation of transfected Cos 1 cells. Phosphorylated p $73 \alpha$ was present predominantly in cytosolic fraction upon Hck over expression (Fig. 5A). When co-expressed with Hck, there was 2.3-fold increase in cytosolic p73 as compared to the cytosolic fraction of $\mathrm{p} 73 \alpha$ transfected alone (Fig. $5 \mathrm{~A})$ suggesting that p73 is stabilized in the cytosolic fraction. Surprisingly, we observed that a fraction of Hck localized to the nucleus. Cross-contamination of the fractions was ruled out by probing for tubulin and PARP.

Unlike other Src family kinases such as Src, Lyn and Fyn [51-55], no evidence is available for nuclear localization of Hck. It was therefore important to evaluate that presence of Hck in the nucleus is not a feature of exogenously expressed protein. We determined the sub-cellular distribution of endogenous Hck in a myeloid cell line HL-60. As shown in Fig. 5B, endogenous Hck distributed to both nuclear and cytosolic compartments as evidenced by subcellular fractionation. To confirm that sub cellular fractions were not contaminated, the fractions were analysed by western blotting for Calnexin (an ER protein, present in post nuclear fraction) and PARP (present only in nuclear fraction). The presence of endogenous Hck in the nucleus was confirmed by indirect immunofluorescence assay. HL-60 cells were differentiated with $10 \mathrm{ng} / \mathrm{ml}$ of 12 O-tetradecanoylphorbol-13-acetate (TPA), which allows cells to adhere to the coverslips. After 24 hours, cells were fixed and immunostained with Hck antibody and analysed by confocal microscopy. The middle section passing through the nucleus was analysed for determination of Hck localization. As shown in Fig. 5C, endogenous Hck localized to the nucleus. The cells were also stained without primary antibody for control. 
A

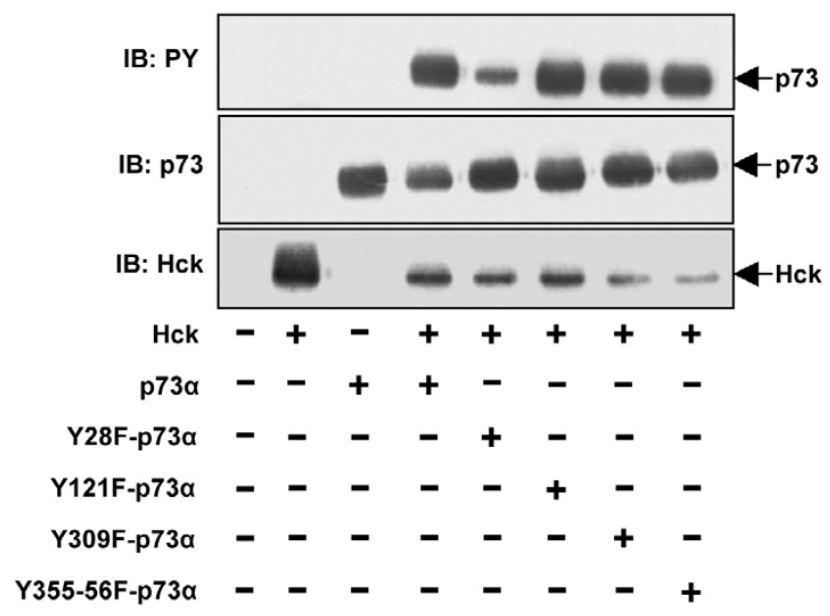

B

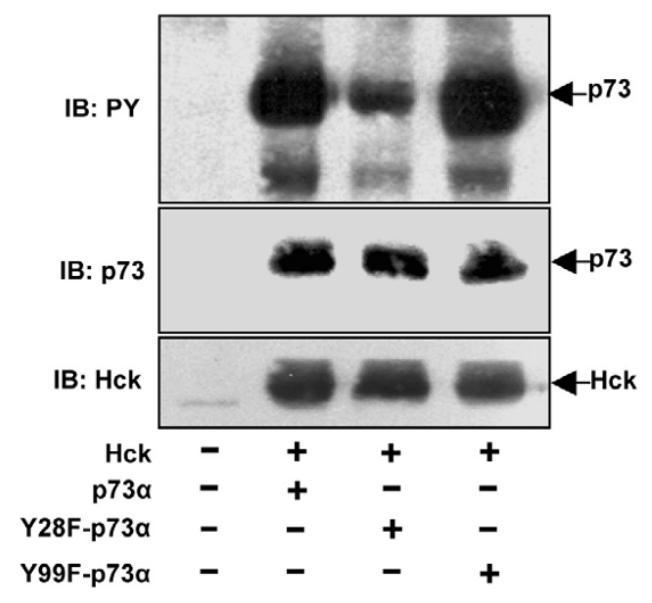

C

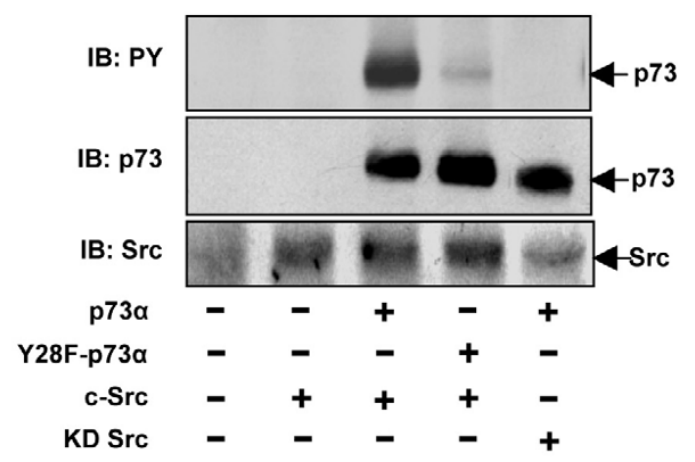

Figure 3

Tyr-28 is the major site of phosphorylation on p73 upon Hck co-expression. (A, B) Cos I cells transfected with indicated combinations of $\mathrm{p} 73$ and Hck plasmids were analyzed by western blotting for $\mathrm{p}$ Tyr. The same blot was reprobed for $\mathrm{p} 73$ and Hck. (C) Src tyrosine kinase phosphorylates p73 $\alpha$ on Tyr-28 residue. CosI cells transfected with p73 $\alpha$, Y28F-p73 $\alpha$ or cSrc and KD-Src were subjected to western blotting for pTyr, p73 and Src. 
A

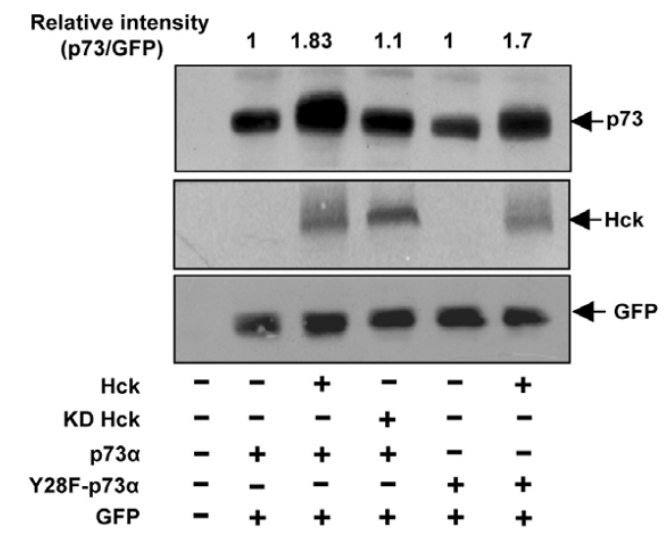

B

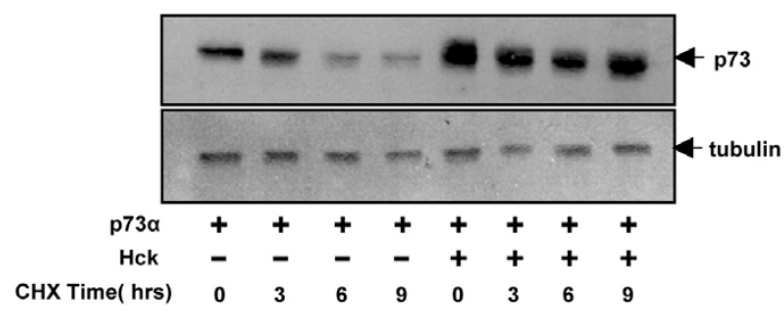

Figure 4

Hck stabilizes p73 $\alpha$ dependent on its kinase activity. (A) Hela cells transfected with GFP (50 ng) and Hck or $\mathrm{KDHck}(200 \mathrm{ng})$ in the presence of $\mathrm{p} 73 \alpha$ or $\mathrm{Y} 28 \mathrm{~F}-\mathrm{p} 73 \alpha(50$ ng) were subjected to western blotting for $\mathrm{p} 73$, Hck and GFP. GFP was used as a transfection efficiency control. (B) Hela cells transfected with $p 73 \alpha$ or $\mathrm{p} 73 \alpha$ and Hck together were treated with cycloheximide $(50 \mu \mathrm{g} / \mathrm{ml})$, harvested at the indicated time periods and immunoblotted for p73 and tubulin. The amount of DNA in transfections was kept constant by the addition of control vector pcDNA3.

\section{Hck suppresses transactivation of $p 73$ targets}

Since interacting proteins and modifications affect the transactivation ability of p73, we determined if Hck coexpression influences p73 activity. We first compared the ability of Hck and c-Abl to regulate p73 activity using PG13 construct that has multiple binding sites for p73. cAbl enhanced p73 $\beta$ activity but Hck co-expression resulted in inhibition of its activity (Fig. 6A). This effect of Hck was also tested using Ipaf promoter. Ipaf, an activator of caspase-1, was recently identified as a p53 target gene induced by DNA damage and was shown to play a role in p53 mediated apoptosis [56]. p73 $\alpha$ even at low level ( 2 ng of plasmid) could strongly transactivate expression of a reporter gene cloned downstream of the Ipaf promoter (Fig. 6B). It was found that Hck repressed activation of Ipaf promoter reporter construct by p73 $\alpha$ (Fig. 6B). Coex- pression of kinase dead (KD) mutant of Hck was also able to repress p $73 \alpha$-mediated transactivation similar to wild type (WT) Hck when tested using Ipaf reporter construct (Fig. 6B). Overexpression of Hck also repressed p73 $\alpha$ induced transactivation of MDM2 promoter, which was independent of kinase activity of Hck, as co-expression of KD mutant of Hck repressed p $73 \alpha$ mediated transactivation similar to WT-Hck (Fig. 6C).

\section{Functional SH3 domain of Hck is required for inhibition of p73 transcriptional activity}

Since Hck inhibited the transcriptional activity of p73 $\alpha$ isoform in a kinase-independent manner, we explored the possibility of the involvement of SH3 domain. Towards this end, a critical tryptophan was mutated to alanine (W93A). This mutation in Hck abolished the binding of SH3 domain to proline rich sequences of proteins as well as enhanced its kinase activity [39]. W93A-Hck (mSH3Hck) was transfected in the presence and absence of p $73 \alpha$ along with Ipaf-CAT reporter construct. mSH3-Hck was not able to inhibit p73 $\alpha$ mediated transcriptional activity of Ipaf promoter whereas WT-Hck showed inhibition (Fig. 6D), suggesting that this inhibition is dependent on functional SH3 domain of Hck. To analyse if this property was unique to Hck, the effect of Src on Ipaf-promoter transactivation was examined. HeLa cells were transfected with p73 $\alpha$ (2 ng) and c-Src or Hck (200 ng each) along with Ipaf-CAT promoter (200 ng) and cell lysates subjected to reporter activity assay. c-Src inhibited p73 $\alpha$ mediated transactivation by $26.21 \%$ as compared to Hck which inhibited the activity by $60 \%$ (Fig. 6E). These results suggest that Hck is a more potent inhibitor of p73 induced Ipaf-promoter transactivation as compared to c-Src indicating the difference in properties between the two members of Src family kinases.

The effect of Hck on p73 induced endogenous gene expression was examined by semi-quantitative reverse transcriptional (RT)-PCR analysis in HeLa cells. Hck and mSH3-Hck were transfected with p73 $\alpha$ in a ratio of $6.5: 1$ and total RNA prepared. These conditions were used to ensure that all p73 expressing cells also co-express Hck. Ectopic expression of $\mathrm{p} 73 \alpha$ resulted in an increase in endogenous Ipaf mRNA levels, and co-expression with WT-Hck resulted in inhibition of expression (Fig. 6F). Coexpression of mSH3-Hck with p73 $\alpha$ did not inhibit p73 $\alpha$ induced Ipaf mRNA levels (Fig. 6F). This was also observed with endogenous MDM2 mRNA levels where coexpression of WT-Hck inhibited MDM2 gene expression significantly and $\mathrm{mSH} 3-\mathrm{Hck}$ coexpression with $\mathrm{p} 73 \alpha$ did not inhibit p73 $\alpha$ induced MDM2 mRNA levels. These results suggested that functional $\mathrm{SH} 3$ domain of Hck is indispensable for repression of p73 transcriptional activity. We assessed the ability of Hck to regulate expression of PUMA, a well-known target of p73. RT-PCR analysis 
A

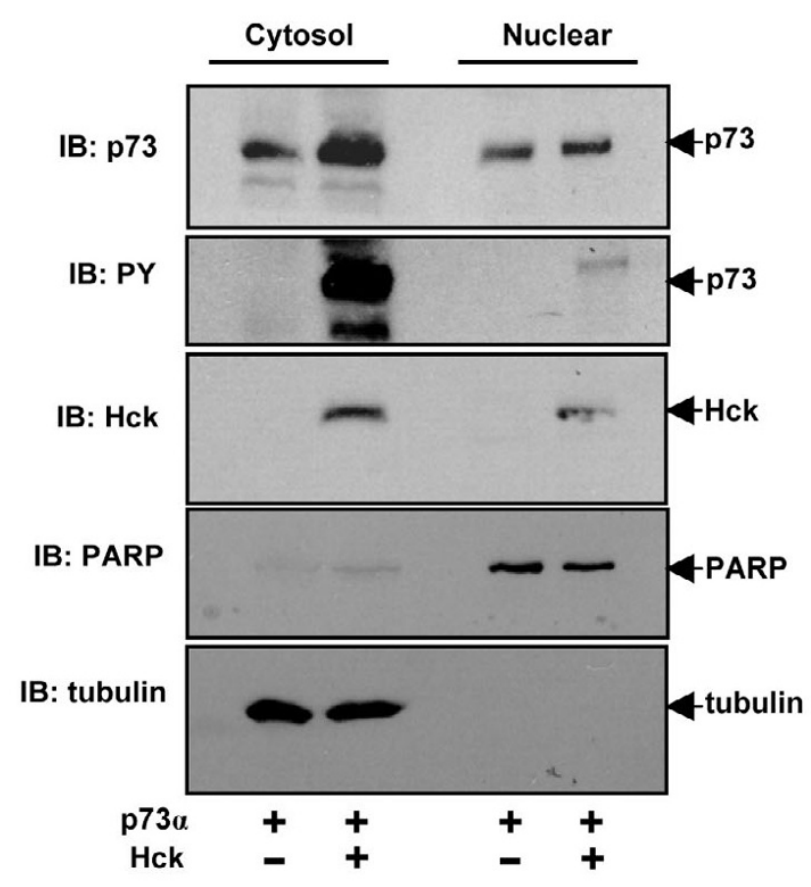

C

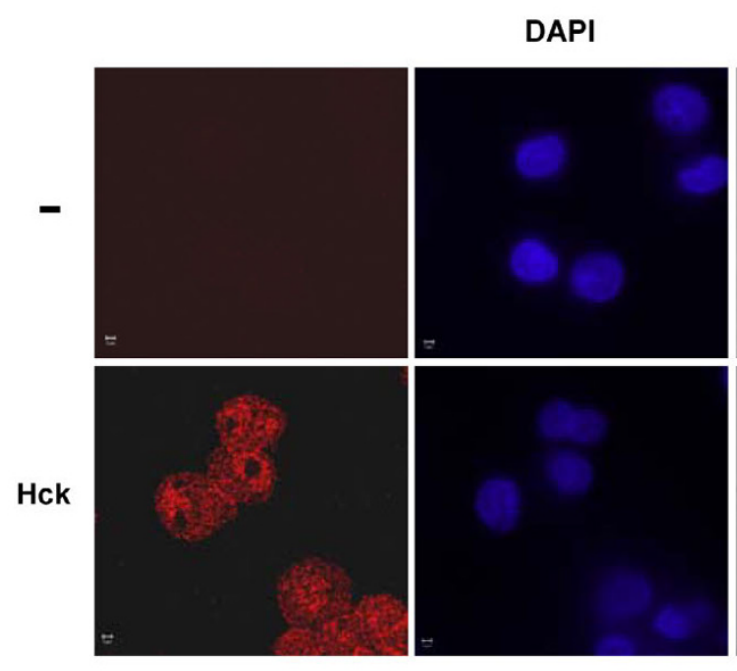

B

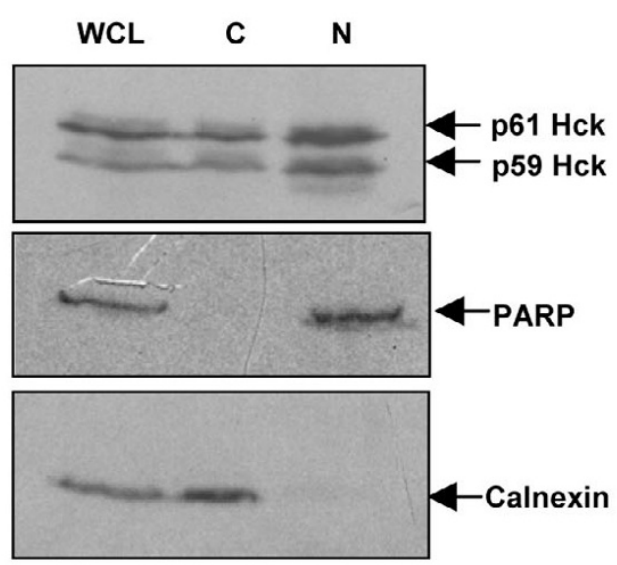

\section{Figure 5}

Sub-cellular localization of Hck and p73 $\alpha$. (A) Cos I cells transiently transfected with p73 $\alpha$ or Hck and p73 $\alpha$ were fractionated into nuclear and cytosolic fractions and analysed by immunoblotting for pTyr, p73 and Hck. The purity of nuclear and cytosolic fractions was confirmed by immunoblotting for PARP and $\alpha$-tubulin. (B) Endogenous Hck in HL-60 cells localizes to both cytosolic and nuclear fractions. HL-60 cells were fractionated into nuclear and cytosolic (post nuclear fraction) fractions and immunoblotted using Hck antibody. The purity of fractions was confirmed by immunoblotting with PARP and Calnexin. WCL indicates whole cell lysates. (C) Localization of endogenous Hck in the nucleus by immunostaining. HL-60 cells were immunostained with Hck antibody after 24 hours of differentiation by TPA $(10 \mathrm{ng} / \mathrm{ml})$ and analysed by confocal microscopy. The image shown is the central section passing through nucleus. The cells were also stained without primary antibody, which served as a control. 
A

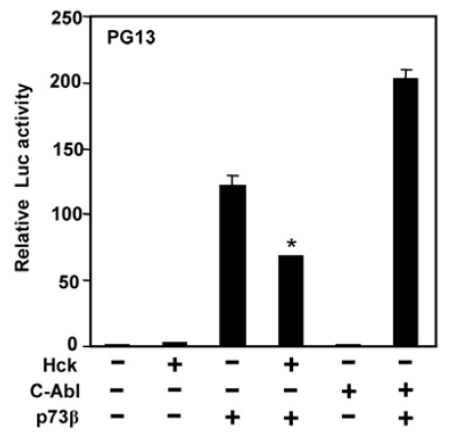

B

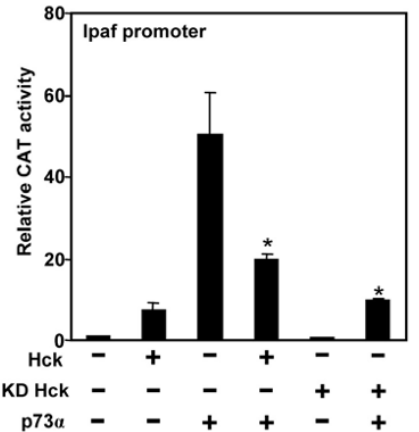

C

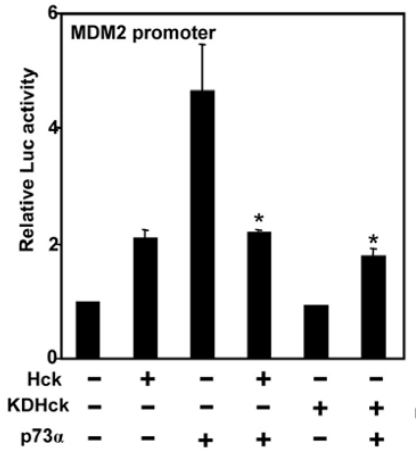

D

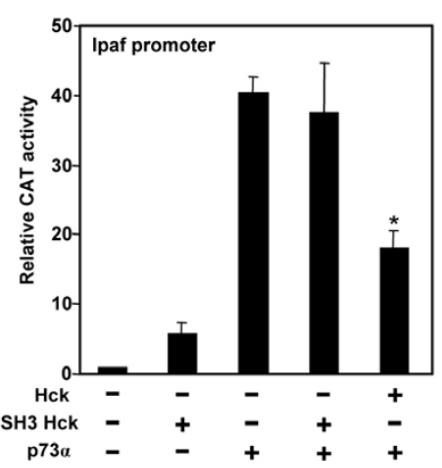

E

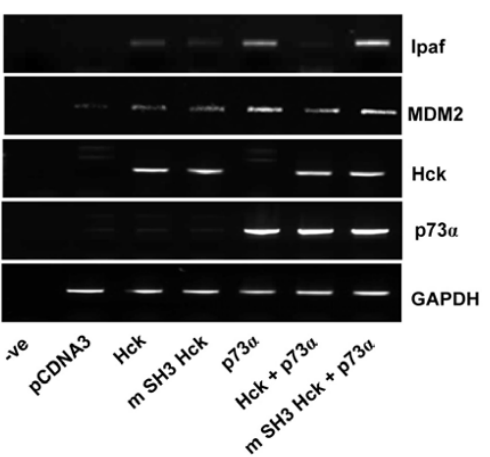

G

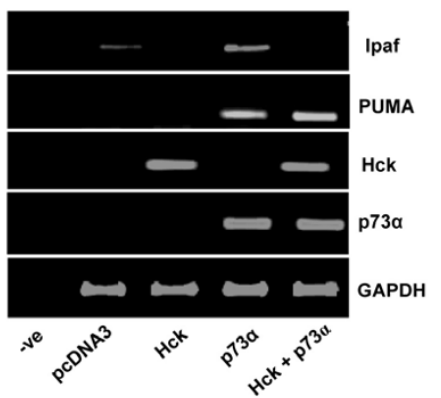

Figure 6

Hck inhibits the transcriptional activity of p73 $\alpha$ and $\beta$ isoforms, dependent on its SH3 domain. (A-D) Hela cells transfected with pCMV- $\beta$ gal (50 ng) and different promoter constructs (100 ng) along with p73 $\alpha$ or p73 $\beta$ and Hck or KD-Hck were subjected to either luciferase or CAT activity measurements. The amount of DNA was kept constant in all transfections to $400 \mathrm{ng}$ by adding pcDNA3. Hck, KD-Hck, mSH3-Hck and c-Abl plasmids were used at 100 ng for different promoter constructs. The amount of $p 73 \alpha$ used was $2 \mathrm{ng}$ for Ipaf-CAT promoter and $50 \mathrm{ng}$ for MDM2-Luc promoter. The amount of $\mathrm{p} 73 \beta$ used was $10 \mathrm{ng}$ for PG I3-Luc promoter. Relative reporter activities were calculated after normalizing with $\beta$-galactosidase activities. Data presented here are mean \pm S.D. of at least three independent experiments, ${ }^{*}$ p $<0.01$. (E) Effect of c-Src on p73 induced Ipaf promoter transctivation. HeLa cells transfected with Ipaf promoter construct along with p73 $\alpha(2 \mathrm{ng})$ and c-Src or Hck (I00 ng) were subjected to CAT activity measurements. Data presented here are mean \pm S.D. of at least three independent experiments, ${ }^{*} \mathrm{p}<0.05$, ${ }^{*} \mathrm{p}<0.0 \mathrm{I}$. (F, G) Total RNA isolated from Hela cells transfected with HA-p73 $\alpha(200 \mathrm{ng})$ or Hck (I $300 \mathrm{ng}$ ) and mSH3 Hck (I300 ng) were subjected to RT-PCR analysis for Ipaf, MDM2 and PUMA gene expression. P73 $\alpha$ and Hck mRNA levels were determined for transfection efficiency control whereas GAPDH mRNA levels were used as an internal control. 
showed that $\mathrm{p} 73 \alpha$ expression upregulates expression of PUMA in HeLa cells. Upon co-expression of Hck with p73 $\alpha$, PUMA expression was not altered under the conditions where Ipaf gene expression was repressed (Fig. 6G). This result shows that Hck may regulate endogenous p73 targets selectively.

\section{Inhibition of p73 $\alpha$ induced apoptosis by Hck}

p73 $\alpha$ expression induces apoptosis in osteosarcoma cell line SAOS2 that is p53-/- [5]. We wished to determine whether repressive effect of Hck on p73 activity is reflected also in its ability to suppress apoptosis. We examined the effect of Hck expression on p73 $\alpha$-induced apoptosis in SAOS 2 cell line. p73 $\alpha$ was overexpressed with and without Hck and cells were scored for apoptosis after immunostaining for p73 and Hck expression. p73 $\alpha$ alone induced apoptosis in 33\% of expressing cells but coexpression with Hck resulted in apoptosis of only $15 \%$ of expressing cells (Fig. 7A). A functional SH3 domain in Hck was required for inhibiting p73-induced apoptosis since the W93A-Hck construct did not show any inhibitory effect. This property was independent of Hck kinase activity as seen by the ability of KD Hck to inhibit p73induced apoptosis (Fig. 7A). The morphology of single and dual expressing cells is shown in Fig. 7B. Further, to assess downstream events of apoptosis, cleaved caspase-3 levels were determined by immunostaining. A large number of p73 $\alpha$ expressing cells showed increased staining of cleaved caspase-3, which is a hallmark for apoptosis (Fig. 7C). Co-expression of Hck along with p $73 \alpha$ showed significant reduction in number of cells expressing cleaved caspase-3, whereas mSH3-Hck coexpression did not affect the number of cells with cleaved caspase-3 in SAOS2 cells (Fig. 7C).

The effect of Hck on p73 induced Ipaf gene expression in SAOS-2 cells was examined. When Hck was co-expressed with p $73 \alpha$, Ipaf expression was reduced significantly (Fig. 7D). This repression was independent of kinase activity of Hck but dependent on functional SH3 domain of Hck (Fig. 7D). We determined the effect of Y28F-p73 $\alpha$ mutation on its ability to transactivate gene expression. Expression of $\mathrm{p} 73 \alpha$ or Y28F-p73 $\alpha$ mutant in SAOS2 cells resulted in an increased expression of Ipaf gene as determined by RT-PCR (Fig. 7E). Co-expression of Hck suppressed p73 $\alpha$-induced as well as Y28F mutant-induced expression of Ipaf mRNA (Fig. 7E). To determine whether some other target of p73 is affected by Y28F mutation, we analysed the induction of 14-3-3 $\sigma$ mRNA (known to be induced by p73 $\alpha$ ) [57] by p73 $\alpha$ as well as by Y28F mutant

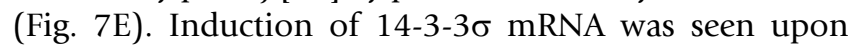
expression of p73 $\alpha$ as well as $\mathrm{Y} 28 \mathrm{~F}$ mutant. Interestingly, there was no suppression of $\mathrm{p} 73 \alpha$ or Y28Fp73 $\alpha$ mutant induced $14-3-3 \sigma$ mRNA by Hck (Fig. 7E). These results suggest that the suppressive effect of Hck on p73-induced gene expression is promoter specific as was also observed in HeLa cells.

Since Hck inhibited p73 induced promoter activation as well as gene expression, this study was also extended to check the ability of Hck to inhibit apoptosis induced by cisplatin, an anti cancer drug known to mediate apoptosis by activation of p73 [12]. SAOS2 cells were transfected with GFP, WT-Hck or mSH3-Hck and immunostained for expressing cells after cisplatin treatment. Quantitation of apoptosis in expressing and nonexpressing cells showed that Hck expression protected $47 \%$ of cells from cisplatin induced apoptosis (Fig. 8A). Neither GFP expression nor mutant SH3 Hck expression inhibited this apoptosis. The protein levels of p73 $\alpha$, Hck and mSH3-Hck were also determined upon cisplatin treatment which is shown in Fig. 8B. The morphology of Hck expressing cells is shown in Fig. 8C.

\section{YAP interacts with Hck and is required for $p$ 73-induced activation of Ipaf promoter}

In an attempt to elucidate the mechanism by which Hck inhibits p73 activity in a target specific manner, we tested the possible involvement of YAP, a molecule that binds to and selectively regulates p73 dependent transactivation $[58,59]$. YAP was first identified as the Src family kinase Yes, interacting protein [60]. We explored the possibility of YAP interacting with Hck in vivo in co-immunoprecipitation experiments. YAP was detected in Hck immunoprecipitates from cells expressing both Hck and YAP and not with control antibody (Fig. 9A). The ability of Hck to interact with YAP was tested in vitro using GST fusion proteins. YAP interacted with GST-SH3-Hck domain and not with GST-mSH3-Hck domain (Fig. 9B).

The role of YAP in p73 $\alpha$ mediated Ipaf promoter transactivation was determined by knock down of YAP using RNAi strategy. YAP shRNA I, II, III and control shRNA I and II were transfected with GFP-YAP in HeLa cells in the ratio of $4: 1$ and whole cell lyastes subjected to immunoblotting with GFP antibody. YAP shRNA I, II and III inhibited the expression of GFP-YAP by $90 \%, 85 \%$ and $71 \%$, respectively, as compared to control shRNA I (Fig. 9C). As can be seen in Fig. 9C, (lower panel), transfection efficiency was comparable as determined by GFP blot which was used as an efficiency control. To check the role of endogenous YAP in p $73 \alpha$-induced Ipaf promoter transactivation, YAP shRNA I, II and control shRNA I were transfected with and without p73 $\alpha$ along with Ipaf-CAT promoter construct and CAT assays performed after 36 hours of transfection. YAP shRNA I and II significantly inhibited $\mathrm{p} 73 \alpha$ mediated Ipaf-promoter transactivation $(P<0.05)$ (Fig. 9D). These results suggest that endogenous YAP is required for $\mathrm{p} 73 \alpha$-induced activation of Ipaf promoter. 
A

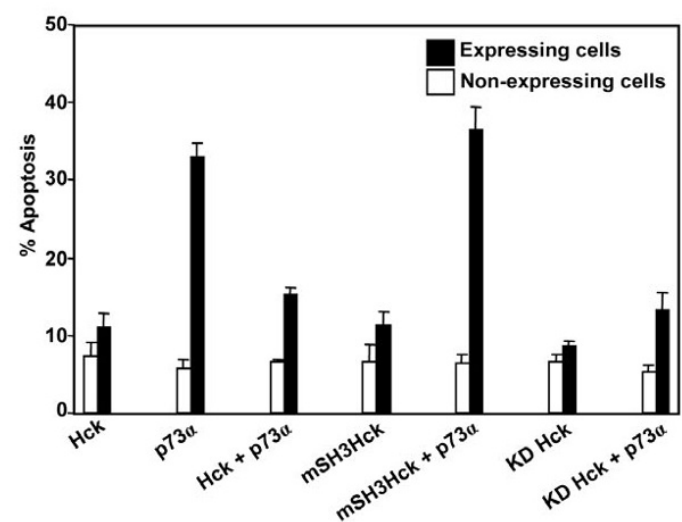

C

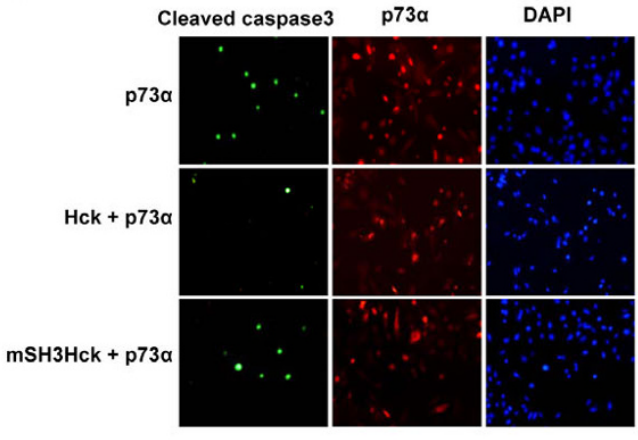

E
B

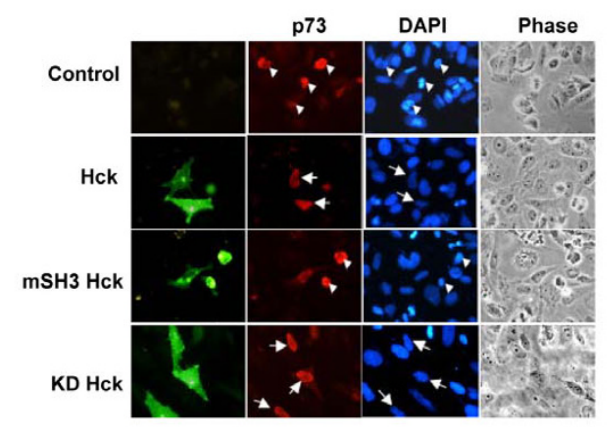

D

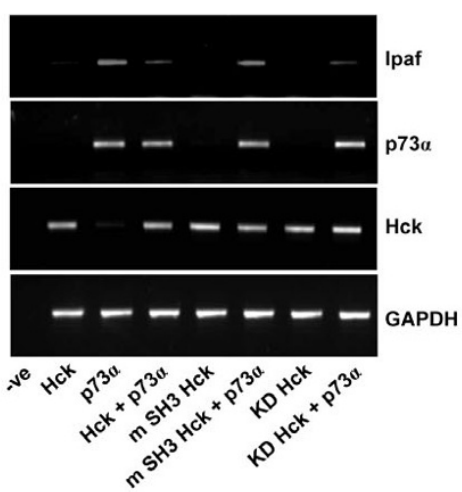

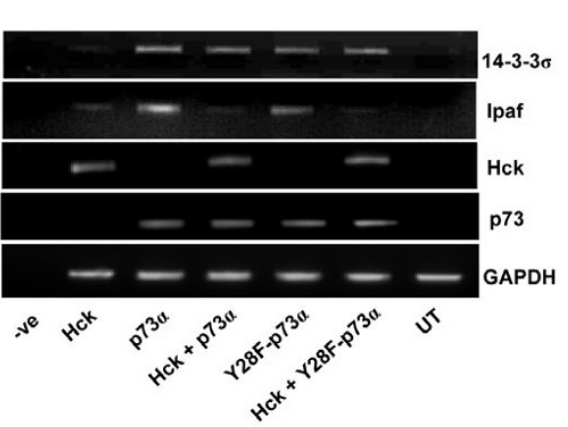

Figure 7

Hck inhibits p73 $\alpha$-induced apoptosis. (A). SAOS- 2 cells transfected with p73 $\alpha$ and Hck, mSH3-Hck or KD-Hck in the ratio of $\mathrm{I}: 3$ were immunostained for $\mathrm{p} 73$ and Hck and the percentage of apoptotic cells was scored among expressing and nonexpressing cells using morphological criteria. Data represent mean \pm S.D. of at least three independent experiments performed on duplicate coverslips. (B) Panels show the morphological features of p73 and Hck expressing cells. Arrowhead shows apoptotic cells and arrows indicate healthy cells. (C) SAOS-2 cells transfected with p73 $\alpha$ and Hck or mSH3-Hck in the ratio of I:3 were immunostained for P73 and cleaved caspase-3 expression. (D) Total RNA isolated from SAOS-2 cells transfected with HA-p73 $\alpha$ (200 ng) with or without Hck (I300 ng), mSH3 Hck (I300 ng) and KD Hck (I 300 ng) were subjected to RT-PCR analysis as described in Fig. 7E. (E) p 73 $\alpha$ transactivation function is independent of Tyr-28 phosphorylation. RT-PCR analysis was carried out using RNA isolated from SAOS-2 cells after transfection with indicated expression constructs. Expression levels of gene products were determined using appropriate primers. (UT indicates untransfected). 
A

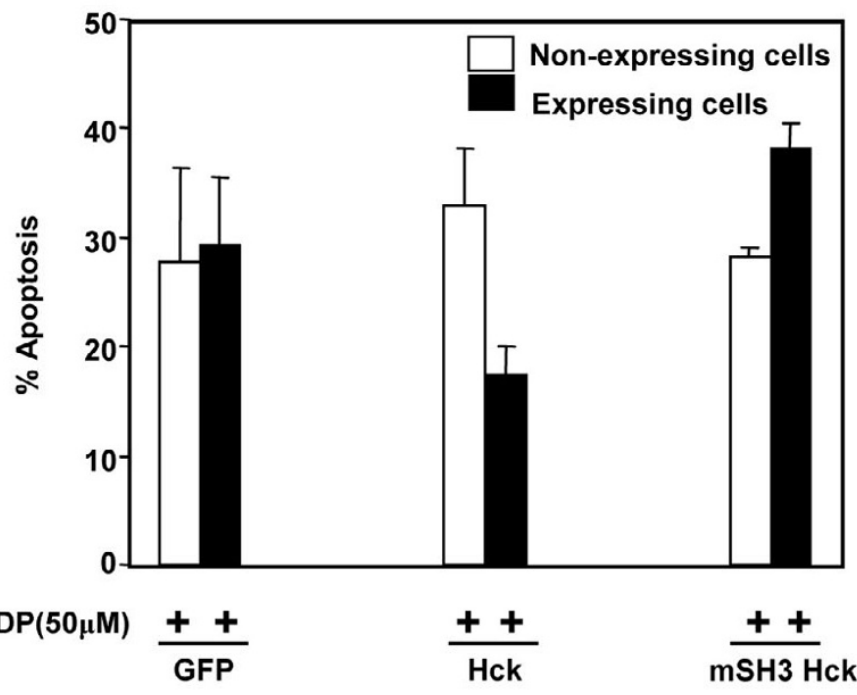

B

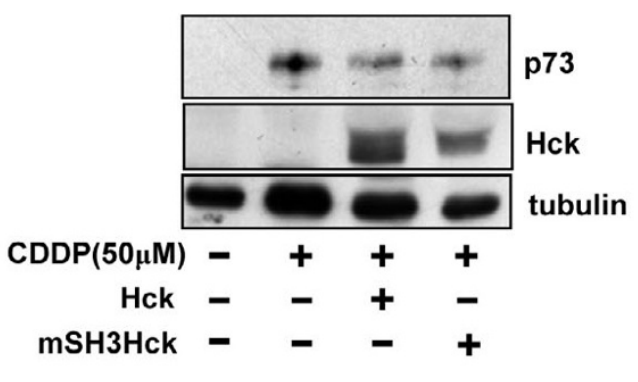

C

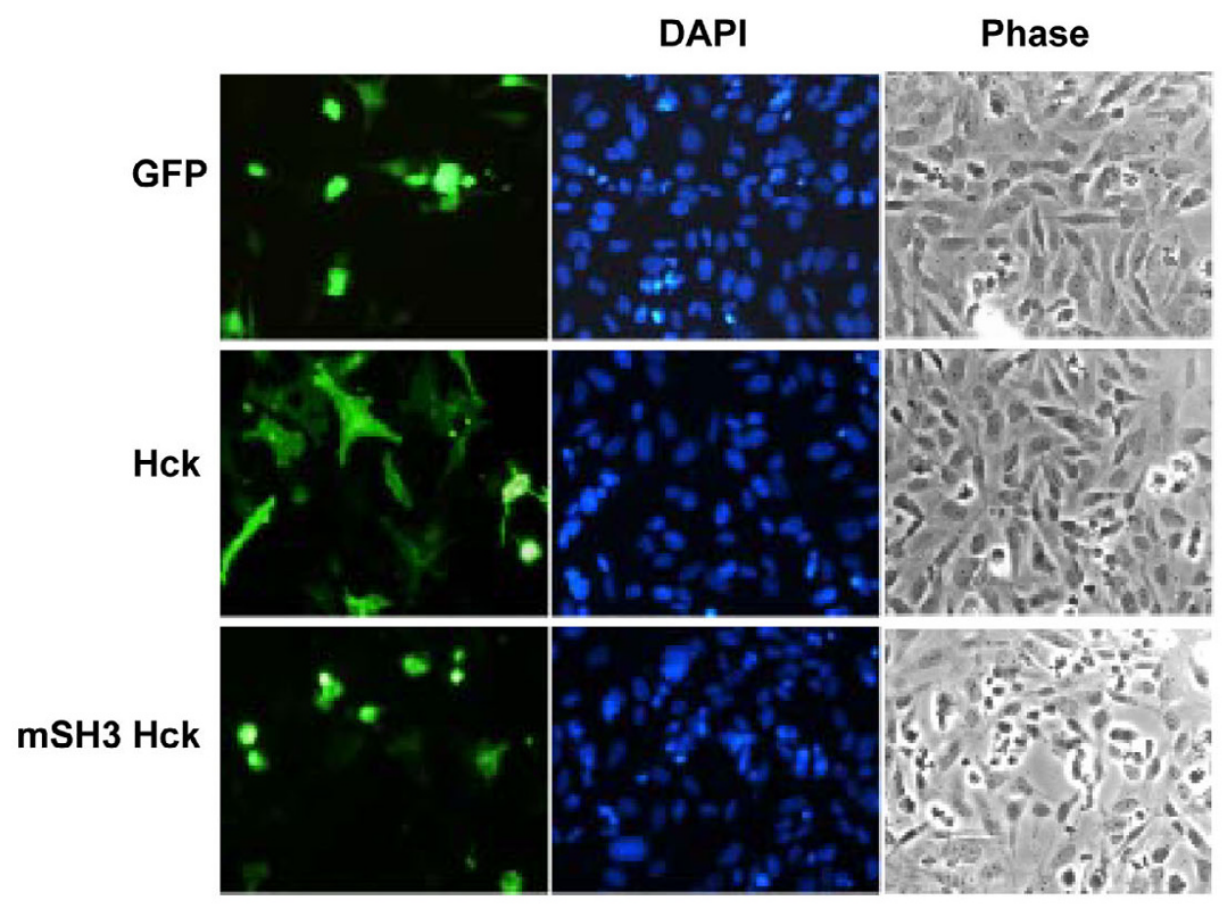

Figure 8

Hck inhibits cisplatin induced apoptosis. (A) SAOS2 cells transfected with GFP, Hck or mSH3 Hck (400 ng) were treated with $50 \mu \mathrm{M}$ cisplatin (CDDP) for 24 hours and immunostained for Hck. The percentage of apoptotic cells was scored among expressing and non-expressing cells using morphological criteria. Data represent mean \pm S.D. of at least three independent experiments. (B) SAOS2 cells transfected with Hck or mSH3 Hck (400 ng) were treated with $50 \mu$ M cisplatin (CDDP) for 24 hours and whole cell lysates were subjected to western blotting with p73 (mouse monoclonal, Imgenex) and Hck antibody. Tubulin was used as loading control. (C) Panels show the expression of GFP, Hck and mSH3 Hck expressing cells. 
A

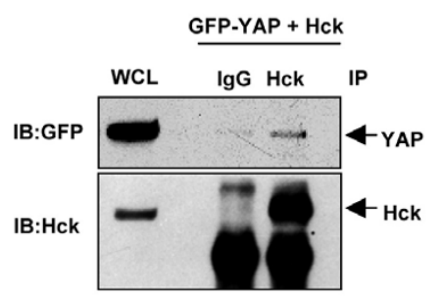

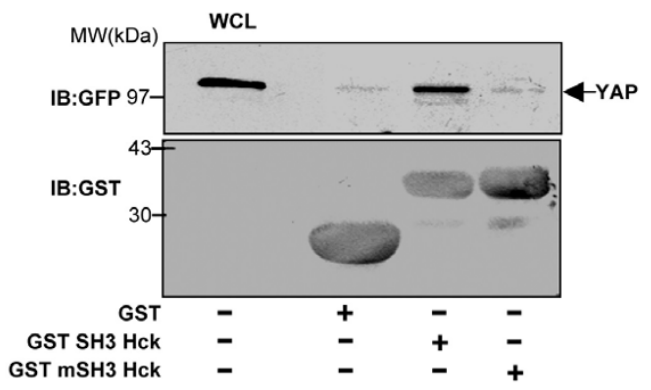

C

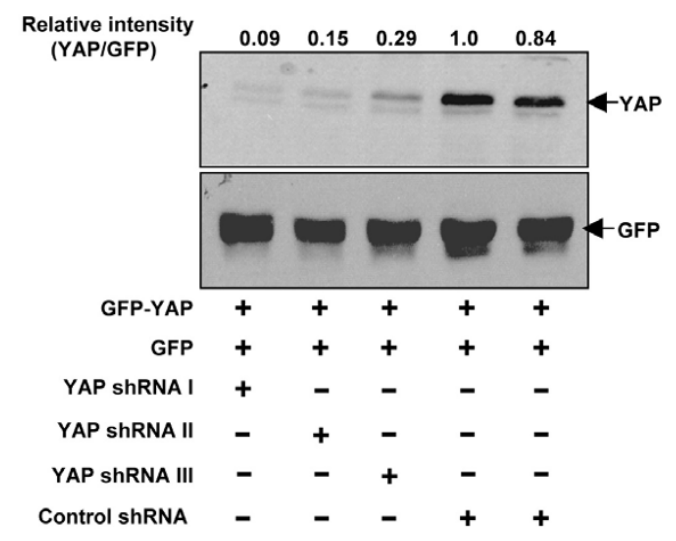

D

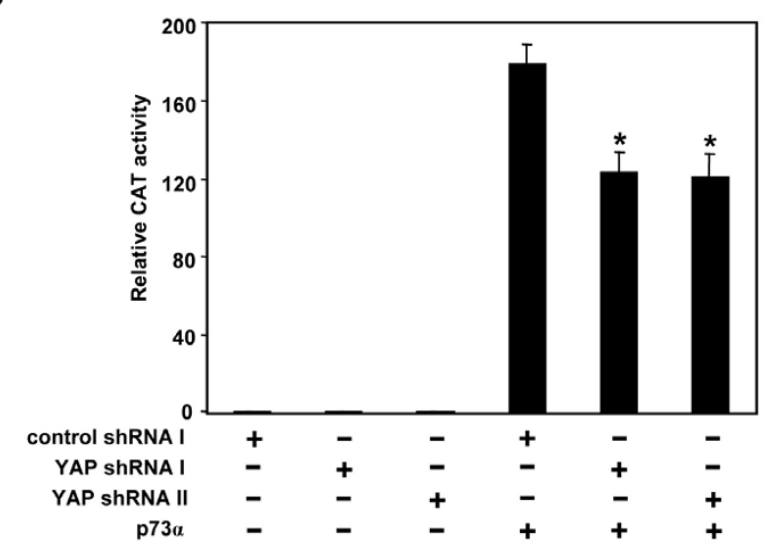

\section{Figure 9}

Hck interacts with YAP and requirement of YAP for transactivation of Ipaf by p73. (A) Cos I cells transiently expressing GFP-YAP with Hck were immunoprecipitated with control rabbit lgG (C) or Hck polyclonal antibody. The immunoprecipitates were resolved by SDS-PAGE and subjected to western blotting to detect YAP and Hck. (B) Extract of Cos I cells transfected with GFP-YAP was incubated with GST, GST-SH3Hck, GST-mSH3-Hck recombinant proteins bound to Glutathione Sepharose beads. Proteins bound to these beads were immunoblotted with GFP and GST antibodies. (C) YAP-shRNA downregulates GFP-YAP expression. Hela cells transfected with GFP-YAP (50 ng) with either control shRNA I and II (200 ng) or YAPshRNA I, II and III (200 ng) subjected to immunoblotting with anti-GFP antibody. GFP (50 ng) was used as transfection efficiency control. (D). Effect of YAP shRNA on p73 $\alpha$ mediated Ipaf promoter transactivation. HeLa cells transiently transfected with YAPshRNA I, II (200 ng) or control shRNA I (200 ng) in the presence or absence of p73 $\alpha$ ( 2 ng) along with lpafCAT promoter construct (I50 ng) and pCMV- $\beta$ Gal (50 ng) were subjected to CAT activity measurements. 


\section{Discussion}

The present study identifies p73 as a substrate and interacting partner of the Src family kinase, Hck. In vitro studies using a GST fusion protein suggest that $p 73 \alpha$ could interact directly with SH3 domain of Hck. Hck represses the transcriptional activity of $\mathrm{p} 73 \alpha$. This repression was observed under conditions where c-Abl co-expression showed enhanced transactivation by p73 indicating that c-Abl and Hck have opposing influence on the function of p73 as a transcriptional activator. This repression was independent of the catalytic activity of Hck but required its SH3 domain. The effect of Hck on p73 activity was also observed at the level of endogenous Ipaf and MDM2 gene expression but did not influence two other known targets

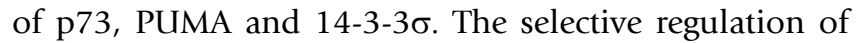
p73 targets by Hck suggests a distinct role for Hck in vivo with respect to modulation of expression of certain genes. Apoptosis induced by exogenously expressed, as well as endogenous p73, was inhibited by Hck, dependent on its $\mathrm{SH} 3$ domain protein interaction function. This property of Hck may therefore be a consequence of its ability to repress target gene induction by $\mathrm{p} 73$.

Hck mediated inhibition of p73 activity may be effected by direct interaction between these two proteins in vivo, or by the involvement of a Hck interacting protein that is required for p73 dependent transcriptional activation. Endogenous as well as exogenously expressed Hck has earlier been shown to localize to plasma membrane, Golgi, secretory granules, nongranular membranes and cytosol [47-50]. Most intracellular functions of Src family kinases have been attributed to their localization to the plasma membranes and cytosolic compartments. More recently tyrosine kinases involved in receptor mediated signaling pathways have been shown to be present in the nucleus and their role in influencing activity of transcription factors has been described [54,61]. Our results suggest that both exogenously expressed as well as endogenous Hck is present to some extent in nuclear compartment of cells. These observations raise the possibility that the inhibition of p73 transcriptional activity by Hck is mediated at least in part by the fraction of Hck present in the nucleus. Cytoplasmic sequestration of p73 by Hck is not likely to explain inhibition of p73 activity by Hck because the level of p73 in the nucleus (which is likely to be the transcriptionally active component) does not decrease upon co-expression of Hck. Hck interaction with p73 directly could alter its ability to bind or transactivate a set of targets selectively.

Our results also show that Hck interacts with YAP, a transcriptional co-activator, which imparts target selectivity to p73. Since YAP was required for maximal activation of Ipaf promoter by p73, it is possible that Hck mediates repression of p73 transcriptional activity through its abil- ity to interact with YAP. Based on the ability of $\mathrm{p} 73 \delta$ to interact with Hck and not with YAP [62], we can infer that Hck and YAP bind to different sequences on p73. Formation of multimolecular complex, whereby both Hck and YAP interact with p73, could be responsible for Hck causing selective repression of p73 target genes. Since Hck can bind to YAP or to p73 through its single SH3 domain, an alternate possibility is that its interaction with YAP may alter the ability of YAP to transactivate p73 targets.

Phosphorylation of p73 by c-Abl at Y99 results in its activation [23]. Our study shows that Hck predominantly targets a tyrosine in the transactivation domain (Y28). This difference in target site beween Hck and c-Abl rules out the possibility of Hck expression resulting in p73 phosphorylation through activation of c-Abl, although Hck is known to activate c-Abl [42]. This modification (Y28 phosphorylation) did not influence the activity of p73 because Y28F mutant showed the same level of activation of Ipaf promoter as WT p73. Hck inhibited Ipaf gene expression induced by $\mathrm{p} 73 \alpha$ as well as Y28F mutant. We also demonstrated that this modification is not a unique property of Hck, since c-Src expression also resulted in predominant phosphorylation of p73 at Y28. In addition, Hck also targets other tyrosine residues (which we have not specifically identified) because Y28 mutant was not totally deficient in phosphorylation.

p73 stabilization has generally been shown to reflect in an increase in its activity [12-14,24]. Our study showed that over- expression of Hck results in stabilization of $\mathrm{p} 73$ protein, dependent on its kinase activity, but this does not lead to an increase in p73 activity. Similarly, it has been reported earlier that interaction of $\mathrm{p} 73$ with MDM2 results in p73 stabilization but inhibition of p73 transcriptional activity [63]. Our results also show that activation of endogenous Hck results in tyrosine phosphorylation of p73. p73 protein levels increase upon differentiation of mylemonocytic cells ([43] and present study). Under these conditions of differentiation, Hck levels and activity are also known to increase. Hck activity mediated signaling may therefore contribute to enhanced protein levels of endogenous p73 upon differentiation. Upon cell fractionation, we observed that Hck co-expression enhanced p73 protein levels only in the cytosolic fraction, but not in the nuclear fraction. Phosphorylated p73 was essentially seen in the cytosolic fraction. p73 localized to nuclear and cytoplasmic compartments may have independent cellular functions just as does p53 [64-66]. Since phosphorylation at Y28 by Hck does not appear to play a significant role in its stability, it is likely that other mechanisms contribute to p73 stabilization dependent on the kinase activity of Hck. Recently, Fyn, a Src family kinase was shown to negatively regulate Itch by tyrosine phosphorylation, impairing its ubiquitinating activity [67]. Since Itch regu- 
lates cellular p73 levels by causing its degradation [68], it is also possible that SFKs may indirectly regulate p73 by preventing its degradation. We have yet to determine the role of p73 stabilized by the kinase activity of Hck in the cytoplasmic compartment.

SFKs modulate diverse signaling cascades dependent on their ability to interact with and phosphorylate various target proteins. In some contexts kinase and adaptor functions can act independently to effect downstream signaling. It therefore, appears that stabilization, which is catalytic activity dependent and suppression of apoptosis, which is SH3 domain interaction dependent, are independent effects of Hck on p73. The functional significance of Y28 phosphorylation of p73 is not clear at present and would require further investigation.

\section{Conclusion}

In conclusion, our results show that the tyrosine kinase Hck interacts with p73 $\alpha$ physically and functionally. Hck and c-Src phosphorylate p $73 \alpha$ at Tyr-28, a novel site of phosphorylation located in the transcriptional activation domain. Transcriptional activity of p73 towards certain target genes is selectively inhibited by Hck independent of its kinase activity. Hck-SH3 domain mediated interactions play an important role in the inhibition of $\mathrm{p} 73$-dependent transcriptional activation of target genes as well as apoptosis.

\section{Methods}

\section{Cell culture and transfections}

HeLa, Cos1, and human osteosarcoma SAOS-2 cells were grown in Dulbecco's modified eagle medium supplemented with $10 \%$ fetal bovine serum and antibiotics. HL60 cells were maintained in RPMI 1640 medium with heat- inactivated $10 \%$ fetal bovine serum and antibiotics. Cultures were maintained in a humidified $37^{\circ} \mathrm{C}$ incubator with $5 \% \mathrm{CO}_{2}$. Transient transfections of HeLa and SAOS- 2 were performed with LipofectAMINE Plus reagent according to the manufacturer's recommendations (Invitrogen). For transfection of Cos1 cells cationic lipid DHDEAB was used as described [50].

\section{Plasmid constructs and antibodies}

The mammalian expression plasmids used were: hemagglutinin (HA) epitope-tagged p73 $\alpha$ or p73 $\beta$ in pcDNA3 (gift from Dr. Gerry Melino, University of Rome, Italy), Human p59 Hck in pcDNA6 (gift from Dr. Todd Miller, State University of New York, Stony Brook), c-Src and K297R-c-Src (from Upstate Biotechnology, Lake Placid, New York), GFP-YAP (gift from Dr. Marius Sudol, Mount Sinai School of Medicine, New York), GST-p73 $\alpha$ (gift from Dr. Giovanni Blandino, Regina Elena Cancer Institute, Italy), p53/p73 responsive promoter construct PG13-Luc (kindly provided by Dr. Bert Vogelstein, Johns
Hopkins University, Baltimore), MDM2-Luc promoter construct (kind gift from Dr. Moshe Oren, Weizmann Institute of Science, Israel), and Ipaf-CAT (pCAT-P2) promoter construct, described by us earlier [56]. Different p73 $\alpha$ mutants (tyrosine to phenyl alanine) were made based on tyrosine phosphorylation sites having high scores using the NetPhos 2.0 program for SFK target sites prediction. Y28F-p73 $\alpha$, Y99F-p73 $\alpha$, Y121F-p73 $\alpha$, Y309Fp73 $\alpha$, Y355-56F-p73 $\alpha$, and Hck mutants, K269E-Hck, W93A-Hck were made by PCR based site directed mutagenesis. Plasmids expressing GST-SH3 and GST-mSH3 domain of Hck (amino acids 72-143) were prepared by cloning the appropriate PCR product into BamH1 and EcoR1 sites of pGEX2T. All the sequences of the constructs were confirmed by using an automated DNA sequencer. The green fluorescence protein (GFP) expression plasmid pEGFP-C1 was from Clontech. Antibodies to p73 (H-79, rabbit ployclonal), Hck (rabbit polyclonal), PY20 (mouse monoclonal), $\alpha$-tubulin (mouse monoclonal), c-Src (goat polyclonal), Calnexin (rabbit polyclonal) and GST (mouse monoclonal) were purchased from SantaCruz Biotechnology. p73 monoclonal antibody clone 1288 was from Imgenex. PARP antibody (rabbit polyclonal) was from Roche.

\section{Construction of vector expressing YAP shRNA}

The YAP shRNA expression vector was constructed using the U6 promoter-based vector essentially as described $[56,71]$. The YAP sequence targeted by shRNA (GenBank ${ }^{\mathrm{TM}}$ accession NM 006106) was from nucleotides 792-812 (for YPI), 1570-1590 (for YPII) and 1254-1274 (for YPIII). The YAP sequences targeted by shRNAs were a) YPI: 5'-GACATCTTCTCGTCAGAGATA-3' b) YPII: 5'-GCTGCCACCATGCTAGATAAA-3' and c) YPIII: 5'-CCTTAACAGTCGCACCTATCA-3'. The vectors expressing shRNA of unrelated sequence of the same length were used as control. All the sequences were confirmed by automated DNA sequencing.

\section{Immunoprecipitation, GST pull down and Western blot analysis}

Cos 1 cells transfected with indicated plasmids were lysed in lysis buffer ( $50 \mathrm{mM}$ Tris-Cl pH 7.5, $150 \mathrm{mM} \mathrm{NaCl}, 10 \%$ glycerol, 0.5\%NP-40, 2 mM EDTA, 2 mM EGTA, 2 mM PMSF, $2 \mathrm{mM} \mathrm{NaF}, 2 \mathrm{mM} \mathrm{Na}_{3} \mathrm{VO}_{4}$ and protease inhibitor (Roche Biochemicals) and the extract was incubated with antibodies overnight at $4{ }^{\circ} \mathrm{C}$. The immune complexes were captured using Protein A/G Plus beads (Santa Cruz) and washed with buffer (50 mM Tris-Cl pH7.5, $150 \mathrm{mM}$ Nacl, $10 \%$ Glycerol, $0.1 \% \mathrm{NP}-40$ ), the proteins were eluted by boiling in $3 \times$ SDS-sample buffer and separated on $8 \%$ SDS PAGE followed by western blotting with the required antibodies using ECL detection reagent (Perkin Elmer). 
For GST pull down assays, cultures of E. Coli DH5 $\alpha$ expressing GST, GST-SH3Hck or GST-mSH3-Hck were induced by $1 \mathrm{mM}$ isopropyl- $\beta$-D-thiogalactopyranosidase (IPTG) for 4 hours at $37^{\circ} \mathrm{C}$. Cells were lysed by addition of cold PBS containing $1 \mathrm{mM}$ PMSF and protease inhibitors (Roche) and sonicated. To this, $1 \%$ Triton-X 100 was added for 30 minutes at $4^{\circ} \mathrm{C}$ for solubilization and then centrifuged to remove insoluble materials. To the supernatant, Glutathione Sepharose beads (50\% slurry) were added and incubated with end-to-end shaking on Rototorque at $4^{\circ} \mathrm{C}$ for 1 hour. Beads were pelleted, washed with PBS containing $0.1 \%$ TritonX-100 and incubated 68 hours with lysates of Cos 1 cells transiently transfected with indicated plasmids. Bound proteins were eluted by boiling in $3 \times$ SDS sample buffer and subjected to immunoblotting.

\section{In-vitro phosphorylation assay}

Purified recombinant human Hck (kind gift from Dr. John Kuriyan, UC Berkeley) was activated for 30 minutes at $37^{\circ} \mathrm{C}$ in $20 \mu \mathrm{l}$ kinase buffer ( $10 \mathrm{mM}$ TRIS-Cl pH 7.5, 0.5 $\mathrm{mM}$ DTT, $10 \mathrm{mM} \mathrm{MgCl}_{2}, 1 \mathrm{mM} \mathrm{MnCl}{ }_{2}$ ) containing $20 \mu \mathrm{M}$ $\mathrm{Na}_{3} \mathrm{VO}_{4}$ and protease inhibitors. Activated Hck (80 nM) was incubated with GST and GST-p73 $\alpha$ in the presence of $3 \mu \mathrm{Ci}$ of $\gamma^{32 \mathrm{P}-A T P}$ for 30 minutes at $37^{\circ} \mathrm{C}$. The reaction was terminated by the addition of $3 \mathrm{X}$-SDS sample buffer followed by boiling for 5 minutes. The proteins were analyzed by $10 \%$ SDS-PAGE and gel was stained with commassie blue to visualize expression of proteins and subsequently dried for phosphor image analysis.

\section{Treatment of cells with mercuric chloride}

HL-60 cells were grown in RPMI medium with 10\% heatinactivated fetal calf serum. These cells were differentiated by the addition of DMSO (1.25\%) for 48 hours. Differentiated cells were subjected to $\mathrm{HgCl}_{2}$ treatment as described by Robbins et al. [46]. Briefly, the cells were washed with phosphate-buffered saline and treated with $0.5 \mathrm{mM} \mathrm{HgCl}_{2}$ for 15 minutes at room temperature before the lysates were subjected to immunoprecipitation with p73 (rabbit polyclonal) antibody.

\section{Cell fractionation}

Transfected Cos1 and HL-60 cells were suspended in cold buffer A (10 mM Hepes-KOH pH7.9, $1.5 \mathrm{mM} \mathrm{MgCl}_{2}, 10$ $\mathrm{mM} \mathrm{KCl}, 1 \mathrm{mM}$ DTT, $1 \mathrm{mM}$ PMSF, $2 \mathrm{mM} \mathrm{Na}_{3} \mathrm{VO}_{4}, 1 \mathrm{mM}$ EDTA, $1 \mathrm{mM}$ EGTA, protease inhibitors) and incubated on ice for 15 minutes. Later, NP-40 was added to $1 \% \mathrm{v} / \mathrm{v}$, vortexed for 20 seconds and incubated on ice for $10 \mathrm{~min}$ utes. Cells were pelleted down at $1500 \mathrm{~g}$ for 5 minutes at $4{ }^{\circ} \mathrm{C}$. Supernatant, which is the cytosolic extract, was resuspended in $3 \times$ SDS sample buffer and boiled for $5 \mathrm{~min}-$ utes. The nuclear pellet was washed thrice with cold buffer A (without NP-40) and re-suspended in $3 \times$ SDS sample buffer, boiled for 5 minutes and resolved by $8 \%$ SDS
PAGE and subsequently immunoblotted with the required antibodies.

\section{Apoptosis assays and Immunofluorescence staining}

Quantitative analysis of apoptotic cells was carried out as described previously $[36,69]$. Cells grown on coverslips were transfected and processed for immunostaining using appropriate antibodies for detection of expressing cells. Cells were mounted in 90\% glycerol containing $1 \mathrm{mg} / \mathrm{ml}$ para-phenylenediamine (antifade) and $0.5 \mu \mathrm{g} / \mathrm{ml}$ DAPI (4'6-diamidino-2 phenylindole) for DNA staining. Cells showing immunofluorescence staining were counted and those cells that showed loss of refraction, condensed chromatin, apoptotic bodies, cell shrinkage were scored as apoptotic. At least 200 expressing cells were counted in each coverslip. The data represent the mean \pm S.D. from at least three independent experiments on duplicate coverslips. Background apoptosis was determined by counting non-expressing cells in the same coverslips. For immunofluorescence staining of endogenous Hck protein, HL-60 cells grown on coverslips were fixed after differentiation for 24 hours with $10 \mathrm{ng} / \mathrm{ml}$ of 12-O-tetradecanoylphorbol-13-acetate (TPA) and stained with Hck (rabbit polyclonal) primary antibody overnight at $4{ }^{\circ} \mathrm{C}$, followed by anti-rabbit Cy3 secondary antibody incubation for 45 minutes.

\section{Reporter assays}

Hela cells were seeded in 24 well plates and transfected with indicated promoter constructs and expression plasmids along with pCMV.SPORT- $\beta$ Gal (Life technologies, Inc.) Total DNA was kept constant to $400 \mathrm{ng}$ by the use of pcDNA3. Cells were lysed in reporter lysis buffer (Promega, Corp.) after 30 hours of transfection and luciferase activity measured by Luciferase repoter assay system (Promega, Corp). CAT assay was carried out as described previously [70]. Relative luciferase or CAT activities were calculated after normalizing with $\beta$-galactosidase enzyme activities.

\section{RT-PCR Analysis}

HeLa and SAOS2 cells were transfected with indicated combination of expression plasmids and after 30 hours of transfection, total RNA was isolated using Trizol reagent (Life Technologies, Inc.). Semi-quantitative PCR was carried out as described previously [70]. Appropriate primers

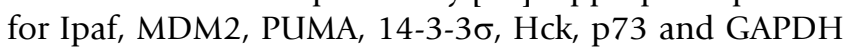
were used for amplification.

\section{Authors' contributions}

All experiments were carried out by PP. VR helped with apoptosis assays. The project was conceived by GS and VR. Design of experiments and interpretation of data was done by all three authors. All authors contributed to writing of the paper and approved the final manuscript. 


\section{Acknowledgements}

We thank, Dr. Gerry Melino, Dr. Giovanni Blandino, Dr. Marius Sudol, Dr. Moshe Oren, Dr. Todd Miller, Dr. John Kuriyan, Dr. Markus Seeliger, Dr. Bert Vogelstein and Dr. Subhashini Sadasivam for providing reagents. PP gratefully acknowledges the Council of Scientific and Industrial Research, India for a senior research fellowship.

\section{References}

I. Kaghad M, Bonnet H, Yang A, Creancier L, Biscan JC, Valent A, Minty A, Chalon P, Lelias JM, Dumont X, et al.: Monoallelically expressed gene related to $\mathrm{p} 53$ at I p36, a region frequently deleted in neuroblastoma and other human cancers. Cell 1997, 90:809-819.

2. Ozaki T, Nakagawara A: p73, a sophisticated p53 family member in the cancer world. Cancer Sci 2005, 96:729-737.

3. Melino G, De LV, Vousden KH: p73: Friend or foe in tumorigenesis. Nat Rev Cancer 2002, 2:605-6I5.

4. Harms K, Nozell S, Chen X: The common and distinct target genes of the p53 family transcription factors. Cell Mol Life Sci 2004, $61: 822-842$.

5. Jost CA, Marin MC, Kaelin WG Jr: p73 is a simian [correction of human] p53-related protein that can induce apoptosis. Nature 1997, 389:191-194.

6. De LV, Melino G: Evolution of functions within the p53/p63/p73 family. Ann N Y Acad Sci 2000, 926:90-100.

7. Zhu J, Jiang J, Zhou W, Chen X: The potential tumor suppressor p73 differentially regulates cellular p53 target genes. Cancer Res 1998, 58:5061-5065.

8. Yang A, Walker N, Bronson R, Kaghad M, Oosterwegel M, Bonnin J, Vagner C, Bonnet H, Dikkes P, Sharpe A, et al.: p73-deficient mice have neurological, pheromonal and inflammatory defects but lack spontaneous tumours. Nature 2000, 404:99-103.

9. Jain N, Gupta S, Sudhakar C, Radha V, Swarup G: Role of p73 in regulating human caspase-I gene transcription induced by interferon-\{gamma\} and cisplatin. J Biol Chem 2005, 280:36664-36673.

10. Irwin MS, Kaelin WG: p53 family update: p73 and p63 develop their own identities. Cell Growth Differ 200I, I 2:337-349.

II. Dobbelstein M, Strano S, Roth J, Blandino G: p73-induced apoptosis: a question of compartments and cooperation. Biochem Biophys Res Commun 2005, 33 I:688-693.

12. Gong JG, Costanzo A, Yang HQ, Melino G, Kaelin WG Jr, Levrero M, Wang JY: The tyrosine kinase c-Abl regulates p73 in apoptotic response to cisplatin-induced DNA damage. Nature 1999, 399:806-809.

13. Miyazaki K, Ozaki T, Kato C, Hanamoto T, Fujita T, Irino S, Watanabe K, Nakagawa T, Nakagawara A: A novel HECT-type E3 ubiquitin ligase, NEDL2, stabilizes p73 and enhances its transcriptional activity. Biochem Biophys Res Commun 2003, 308: I06-I I3.

14. Kramer S, Ozaki T, Miyazaki K, Kato C, Hanamoto T, Nakagawara A: Protein stability and function of p73 are modulated by a physical interaction with RanBPM in mammalian cultured cells. Oncogene 2005, 24:938-944.

15. Stros M, Ozaki T, Bacikova A, Kageyama H, Nakagawara A: HMGB I and HMGB2 cell-specifically down-regulate the p53- and p73-dependent sequence-specific transactivation from the human Bax gene promoter. J Biol Chem 2002, 277:7। 57-7I64.

16. Ozaki T, Watanabe K, Nakagawa T, Miyazaki K, Takahashi M, Nakagawara $A$ : Function of p73, not of p53, is inhibited by the physical interaction with RACKI and its inhibitory effect is counteracted by pRB. Oncogene 2003, 22:323I-3242.

17. Fulco M, Costanzo A, Merlo P, Mangiacasale R, Strano S, Blandino G, Balsano $C$, Lavia $P$, Levrero $M:$ p73 is regulated by phosphorylation at the G2/M transition. J Biol Chem 2003, 278:49196-49202.

18. Gaiddon C, Lokshin M, Gross I, Levasseur D, Taya Y, Loeffler JP, Prives C: Cyclin-dependent kinases phosphorylate p73 at threonine 86 in a cell cycle-dependent manner and negatively regulate p73. J Biol Chem 2003, 278:2742I-2743I.

19. Aqeilan RI, Pekarsky Y, Herrero JJ, Palamarchuk A, Letofsky J, Druck T, Trapasso F, Han SY, Melino G, Huebner K, et al.: Functional association between $W$ wox tumor suppressor protein and p73, a p53 homolog. Proc Natl Acad Sci USA 2004, I 0 I:440 I-4406.

20. Hanamoto T, Ozaki T, Furuya K, Hosoda M, Hayashi S, Nakanishi M, Yamamoto H, Kikuchi H, Todo S, Nakagawara A: Identification of protein kinase A catalytic subunit beta as a novel binding partner of p73 and regulation of p73 function. J Biol Chem 2005, 280: | $6665-16675$.

21. Watanabe K, Ozaki T, Nakagawa T, Miyazaki K, Takahashi M, Hosoda M, Hayashi S, Todo S, Nakagawara A: Physical interaction of p73 with c-Myc and MMI, a c-Myc-binding protein, and modulation of the p73 function. J Biol Chem 2002, 277:I5II3-I5I23.

22. Agami R, Blandino G, Oren M, Shaul Y: Interaction of c-Abl and p73alpha and their collaboration to induce apoptosis. Nature 1999, 399:809-8|3.

23. Yuan ZM, Shioya H, Ishiko T, Sun X, Gu J, Huang YY, Lu H, Kharbanda $S$, Weichselbaum $R$, Kufe $D:$ p73 is regulated by tyrosine kinase c-Abl in the apoptotic response to DNA damage. Nature 1999, 399:814-817.

24. Sanchez-Prieto R, Sanchez-Arevalo VJ, Servitja JM, Gutkind JS: Regulation of p73 by c-Abl through the p38 MAP kinase pathway. Oncogene 2002, 2 I:974-979.

25. Thomas SM, Brugge JS: Cellular functions regulated by Src family kinases. Annu Rev Cell Dev Biol 1997, I 3:5 I3-609.

26. Briggs SD, Sharkey M, Stevenson M, Smithgall TE: SH3-mediated Hck tyrosine kinase activation and fibroblast transformation by theNef protein of HIV-I. J Biol Chem 1997, 272:I7899-I7902.

27. Liu $X$, Pawson T: Biochemistry of the Src protein-tyrosine kinase: regulation by $\mathbf{S H} 2$ and SH3 domains. Recent Prog Horm Res 1994, 49: 149-60.

28. Ernst M, Gearing DP, Dunn AR: Functional and biochemical association of Hck with the LIF/IL-6 receptor signal transducing subunit gp I 30 in embryonic stem cells. EMBO J 1994 , | 3: | 574- I584.

29. Quintrell N, Lebo R, Varmus H, Bishop JM, Pettenati MJ, Le Beau MM, Diaz MO, Rowley JD: Identification of a human gene (HCK) that encodes a protein-tyrosine kinase and is expressed in hemopoietic cells. Mol Cell Biol 1987, 7:2267-2275.

30. Ziegler SF, Marth JD, Lewis DB, Perlmutter RM: Novel proteintyrosine kinase gene (hck) preferentially expressed in cells of hematopoietic origin. Mol Cell Biol 1987, 7:2276-2285.

31. Lock P, Ralph S, Stanley E, Boulet I, Ramsay R, Dunn AR: Two isoforms of murine hck, generated by utilization of alternative translational initiation codons, exhibit different patterns of subcellular localization. Mol Cell Biol I991, I I:4363-4370.

32. Bosco MC, Curiel RE, Zea AH, Malabarba MG, Ortaldo JR, EspinozaDelgado I: IL-2 signaling in human monocytes involves the phosphorylation and activation of p59hck. J Immunol 2000, I 64:4575-4585.

33. Ward AC, Monkhouse JL, Csar XF, Touw IP, Bello PA: The Src-like tyrosine kinase Hck is activated by granulocyte colony-stimulating factor (G-CSF) and docks to the activated G-CSF receptor. Biochem Biophys Res Commun 1998, 25 I:I I7-123.

34. English BK, Ihle JN, Myracle A, Yi T: Hck tyrosine kinase activity modulates tumor necrosis factor production by murine macrophages. J Exp Med 1993, 178:1017-1022.

35. Boulet I, Ralph S, Stanley E, Lock P, Dunn AR, Green SP, Phillips WA: Lipopolysaccharide- and interferon-gamma-induced expression of hck and lyn tyrosine kinases in murine bone marrowderived macrophages. Oncogene 1992, 7:703-710.

36. Shivakrupa R, Radha V, Sudhakar C, Swarup G: Physical and functional interaction between Hck tyrosine kinase and guanine nucleotide exchange factor C3G results in apoptosis, which is independent of C3G catalytic domain. J Biol Chem 2003, 278:52|88-52।94.

37. Scholz G, Cartledge K, Dunn AR: Hck enhances the adherence of lipopolysaccharide-stimulated macrophages via $\mathrm{Cbl}$ and phosphatidylinositol 3-kinase. J Biol Chem 2000, 275: 14615-14623.

38. Scott MP, Zappacosta F, Kim EY, Annan RS, Miller WT: Identification of novel $\mathrm{SH} 3$ domain ligands for the Src family kinase Hck. Wiskott-Aldrich syndrome protein (WASP), WASP. interacting protein (WIP), and ELMOI. J Biol Chem 2002, 277:28238-28246.

39. Schreiner SJ, Schiavone AP, Smithgall TE: Activation of STAT3 by the Src family kinase Hck requires a functional SH3 domain. J Biol Chem 2002, 277:45680-45687.

40. Yokoyama N, Miller WT: Biochemical properties of the Cdc42associated tyrosine kinase ACKI. Substrate specificity, authphosphorylation, and interaction with Hck. J Biol Chem 2003, 278:477|3-47723. 
4I. Tsai KK, Yuan ZM: c-Abl stabilizes $\mathbf{p 7 3}$ by a phosphorylationaugmented interaction. Cancer Res 2003, 63:34I8-3424.

42. Tanis KQ, Veach D, Duewel HS, Bornmann WG, Koleske AJ: Two distinct phosphorylation pathways have additive effects on Abl family kinase activation. Mol Cell Biol 2003, 23:3884-3896.

43. Tschan MP, Grob TJ, Peters UR, Laurenzi VD, Huegli B, Kreuzer KA Schmidt CA, Melino G, Fey MF, Tobler A, et al.: Enhanced p73 expression during differentiation and complex p73 isoforms in myeloid leukemia. Biochem Biophys Res Commun 2000, 277:62-65.

44. Linnekin D, Howard OM, Park L, Farrar W, Ferris D, Longo DL: Hck expression correlates with granulocyte-macrophage colonystimulating factor-induced proliferation in HL-60 cells. Blood 1994, 84:94-103.

45. Howlett CJ, Bisson SA, Resek ME, Tigley AW, Robbins SM: The proto-oncogene $\mathrm{pl} 20(\mathrm{Cbl})$ is a downstream substrate of the Hck protein-tyrosine kinase. Biochem Biophys Res Commun 1999, 257:129-138.

46. Robbins SM, Quintrell NA, Bishop JM: Mercuric chloride activates the Src-family protein tyrosine kinase, $\mathrm{Hck}$ in myelomonocytic cells. Eur J Biochem 2000, 267:7201-7208.

47. Mohn H, Le C V, Fischer S, Maridonneau-Parini I: The src-family protein-tyrosine kinase $\mathrm{p} 59 \mathrm{hck}$ is located on the secretory granules in human neutrophils and translocates towards the phagosome during cell activation. Biochem J 1995, 309:657-665.

48. Robbins SM, Quintrell NA, Bishop JM: Myristoylation and differential palmitoylation of the HCK protein-tyrosine kinases govern their attachment to membranes and association with caveolae. Mol Cell Biol 1995, 15:3507-35I5.

49. Astarie-Dequeker C, Carreno S, Cougoule C, Maridonneau-Parini I: The protein tyrosine kinase Hck is located on lysosomal vesicles that are physically and functionally distinct from CD63positive lysosomes in human macrophages. J Cell Sci 2002, I I 5:81-89.

50. Radha V, Rajanna A, Swarup G: Phosphorylated guanine nucleotide exchange factor $C 3 G$, induced by pervanadate and Src family kinases localizes to the Golgi and subcortical actin cytoskeleton. BMC Cell Biol 2004, 20(5):3I.

51. Zhao Y, Sudol M, Hanafusa H, Krueger J: Increased tyrosine kinase activity of c-Src during calcium-induced keratinocyte differentiation. Proc Natl Acad Sci USA 1992, 89:8298-8302.

52. David-Pfeuty T, Bagrodia S, Shalloway D: Differential localization patterns of myristoylated and nonmyristoylated c-Src proteins in interphase and mitotic c-Src overexpresser cells. J Cell Sci 1993, 105:613-628.

53. Radha V, Nambirajan S, Swarup G: Association of Lyn tyrosine kinase with the nuclear matrix and cell-cycle-dependent changes in matrix-associated tyrosine kinase activity. Eur J Biochem 1996, 236:352-359.

54. Ren X, Cao C, Zhu L, Yoshida K, Kharbanda S, Weichselbaum R, Kufe $D$ : Lyn tyrosine kinase inhibits nuclear export of the p53 tumor suppressor. Cancer Biol Ther 2002, 1:703-708.

55. He Z, Cho YY, Ma WY, Choi HS, Bode AM, Dong Z: Regulation of ultraviolet B-induced phosphorylation of histone $\mathrm{H} 3$ at serine 10 by Fyn kinase. J Biol Chem 2005, 280:2446-2454.

56. Sadasivam S, Gupta S, Radha V, Batta K, Kundu TK, Swarup G: Caspase- $I$ activator Ipaf is a p53-inducible gene involved in apoptosis. Oncogene 2005, 24(4):627-636.

57. Fontemaggi G, Kela I, Amariglio N, Rechavi G, Krishnamurthy J Strano S, Sacchi A, Givol D, Blandino G: Identification of direct p73 target genes combining DNA microarray and chromatin immunoprecipitation analyses. I Biol Chem 2002, 277:43359-43368.

58. Strano S, Munarriz E, Rossi M, Castagnoli L, Shaul Y, Sacchi A, Oren M, Sudol M, Cesareni G, Blandino G: Physical interaction with Yes-associated protein enhances p73 transcriptional activity. J Biol Chem 2001, 276: 15164-15173.

59. Strano S, Monti O, Pediconi N, Baccarini A, Fontemaggi G, Lapi E, Mantovani F, Damalas A, Citro G, Sacchi A, et al: The transcriptional coactivator Yes-associated protein drives p73 genetarget specificity in response to DNA Damage. Mol Cell 2005, 1 8:447-459.

60. Sudol M: Yes-associated protein (YAP65) is a proline-rich phosphoprotein that binds to the $\mathrm{SH}_{3}$ domain of the Yes proto-oncogene product. Oncogene 1994, 9:2 145-2I52.
61. Nilsson J, Bjursell G, Kannius-Janson M: Nuclear Jak2 and transcription factor NFI-C2: a novel mechanism of prolactin signaling in mammary epithelial cells. Mol Cell Biol 2006, 26:5663-5674.

62. Strano S, Munarriz E, Rossi M, Castagnoli L, Shaul Y, Sacchi A, Oren M, Sudol M, Cesareni G, Blandino G: Physical interaction with Yes-associated protein enhances p73 transcriptional activity. J Biol Chem 200I, 276:15164-15173.

63. Zeng X, Chen L, Jost CA, Maya R, Keller D, Wang X, Kaelin WG Jr, Oren M, Chen J, Lu H: MDM2 suppresses p73 function without promoting p73 degradation. Mol Cell Biol 1999, 19:3257-3266.

64. Mihara M, Erster S, Zaika A, Petrenko O, Chittenden T, Pancoska P, Moll UM: p53 has a direct apoptogenic role at the mitochondria. Mol Cell 2003, I I:577-590.

65. Chipuk JE, Green DR: Cytoplasmic p53: bax and forward. Cell Cycle 2004, 3:429-43I.

66. Marchenko ND, Wolff S, Erster S, Becker K, Moll UM: Monoubiquitylation promotes mitochondrial p53 translocation. EMBO J 2007, 26:923-934.

67. Yang C, Zhou W, Jeon MS, Demydenko D, Harada Y, Zhou H, Liu YC Negative regulation of the E3 ubiquitin ligase itch via Fynmediated tyrosine phosphorylation. Mol Cell 2006, 2I:I35-I4I.

68. Rossi M, De LV, Munarriz E, Green DR, Liu YC, Vousden KH, Cesareni G, Melino G: The ubiquitin-protein ligase Itch regulates p73 stability. EMBO J 2005, 24:836-848.

69. Radha V, Sudhakar C, Swarup G: Induction of p53 dependent apoptosis upon overexpression of a nuclear protein tyrosine phosphatase. FEBS Lett 1999, 453:308-3|2.

70. Gupta S, Radha V, Furukawa Y, Swarup G: Direct transcriptional activation of human caspase-I by tumor suppressor p53. J Biol Chem 200I, 276: I0585-10588.

7I. Yu JY, DeRuiter SL, Turner DL: RNA interference by expression of short-interfering RNAs and hairpin RNAs in mammalian cells. Proc Natl Acad Sci USA 2002, 99:6047-6052.

Publish with Bio Med Central and every scientist can read your work free of charge

"BioMed Central will be the most significant development for disseminating the results of biomedical research in our lifetime. "

Sir Paul Nurse, Cancer Research UK

Your research papers will be:

- available free of charge to the entire biomedical community

- peer reviewed and published immediately upon acceptance

- cited in PubMed and archived on PubMed Central

- yours - you keep the copyright
BioMedcentral 